\title{
Controls of outbursts of moraine-dammed lakes in the greater Himalayan region
}

\author{
Melanie Fischer $^{1}$, Oliver Korup ${ }^{1,2}$, Georg Veh ${ }^{1}$, and Ariane Walz ${ }^{1}$ \\ ${ }^{1}$ Institute of Environmental Science and Geography, University of Potsdam, 14476 Potsdam, Germany \\ ${ }^{2}$ Institute of Geosciences, University of Potsdam, 14476 Potsdam, Germany
}

Correspondence: Melanie Fischer (melaniefischer@uni-potsdam.de)

Received: 2 November 2020 - Discussion started: 16 December 2020

Revised: 28 June 2021 - Accepted: 6 July 2021 - Published: 30 August 2021

\begin{abstract}
Glacial lakes in the Hindu Kush-KarakoramHimalayas-Nyainqentanglha (HKKHN) region have grown rapidly in number and area in past decades, and some dozens have drained in catastrophic glacial lake outburst floods (GLOFs). Estimating regional susceptibility of glacial lakes has largely relied on qualitative assessments by experts, thus motivating a more systematic and quantitative appraisal. Before the backdrop of current climate-change projections and the potential of elevation-dependent warming, an objective and regionally consistent assessment is urgently needed. We use an inventory of 3390 moraine-dammed lakes and their documented outburst history in the past four decades to test whether elevation, lake area and its rate of change, glaciermass balance, and monsoonality are useful inputs to a probabilistic classification model. We implement these candidate predictors in four Bayesian multi-level logistic regression models to estimate the posterior susceptibility to GLOFs. We find that mostly larger lakes have been more prone to GLOFs in the past four decades regardless of the elevation band in which they occurred. We also find that including the regional average glacier-mass balance improves the model classification. In contrast, changes in lake area and monsoonality play ambiguous roles. Our study provides first quantitative evidence that GLOF susceptibility in the HKKHN scales with lake area, though less so with its dynamics. Our probabilistic prognoses offer improvement compared to a random classification based on average GLOF frequency. Yet they also reveal some major uncertainties that have remained largely unquantified previously and that challenge the applicability of single models. Ensembles of multiple models could be a viable alternative for more accurately classifying the susceptibility of moraine-dammed lakes to GLOFs.
\end{abstract}

\section{Introduction}

Glacial lake outburst floods (GLOFs) involve the sudden release and downstream propagation of water and sediment from naturally impounded meltwater lakes (Costa and Schuster, 1987; Emmer, 2017). About one third of the 25000 glacial lakes in the Hindu Kush-KarakoramHimalayas-Nyainqentanglha (HKKHN) region are dammed by moraines, and some of these are potentially unstable (Maharjan et al., 2018). Such impounded meltwater can overtop or incise dams rapidly with catastrophic consequences downstream (Costa and Schuster, 1987; Evans and Clague, 1994). High Mountain Asian countries are among the most affected by these abrupt floods if considering both damage and fatalities (Carrivick and Tweed, 2016). For example, in June 2013, a GLOF from Chorabari Lake in the Indian state of Uttarakhand caused $>6000$ deaths in what is known as the "Kedarnath disaster" (Allen et al., 2016). The peak discharges of GLOFs can be orders of magnitude higher than those of seasonal floods. GLOFs can move large amounts of sediment, widen mountain channels, undermine hillslopes, and thus increase the hazard to local communities (Cenderelli and Wohl, 2003; Cook et al., 2018). Still, GLOFs in the HKKHN are rare and have occurred at an unchanged rate of about 1.3 per year in the past four decades (Veh et al., 2019). Ice avalanches and glacier calving are the most frequently reported triggers of GLOFs in the HKKHN (Richardson and Reynolds, 2000; Rounce et al., 2016). Most dated outbursts have occurred between June and October and might be linked to high lake levels fed by monsoonal precipitation and summer ablation of glaciers (Richardson and Reynolds, 2000). The Kedarnath GLOF is the only case attributed to a rain-on- 
snow event early in the monsoon season (Allen et al., 2016). This particularly destructive GLOF underlines the need for understanding better how and why meltwater lakes can be susceptible to sudden outburst triggered by rainstorms, especially given projected impacts of atmospheric warming on the high-mountain cryosphere.

Current scenarios entail that atmospheric warming may change the susceptibility of HKKHN glacial lakes to sudden outburst floods: the IPCC's (Intergovernmental Panel on Climate Change) most recent projections attribute the decay of low-lying glaciers and permafrost to increases in lake number and area because of rising air temperatures, more frequent rain-on-snow events at higher elevations, and changes in precipitation seasonality (Hock et al., 2019). Air surface temperature in the HKKHN rose by about $0.1{ }^{\circ} \mathrm{C}$ per decade from 1901 to 2014 (Krishnan et al., 2019), likely having reduced snowfall, altered permafrost distribution, and accelerated glacier melt at lower elevations (Hock et al., 2019). Ice loss in the Himalayas has significantly increased in the past four decades, from $-0.22 \pm 0.13 \mathrm{~m}$ w.e. $\mathrm{yr}^{-1}$ (metres of water equivalent per year) between 1975 and 2000 to $-0.43 \pm 0.14 \mathrm{~m}$ w.e. $\mathrm{yr}^{-1}$ between 2000 and 2016 (Maurer et al., 2019). Parts of this meltwater have been trapped in glacial lakes that have expanded by approximately $14 \%$ between 1990 and 2015 (Nie et al., 2017). King et al. (2019) found that Himalayan glaciers terminating in lakes had higher rates of mass loss since the 1970s than those not in direct contact with a glacial lake. The notion of elevationdependent warming (EDW) posits that increases in air temperature are most pronounced at higher elevations (Hock et al., 2019; Pepin et al., 2015). EDW has affected cold temperature metrics, including the number of frost days and minima of near-surface air temperature in the HKKHN in the past decades (Krishnan et al., 2019; Palazzi et al., 2017). Essentially, all scenarios of atmospheric warming concern aspects of elevation, glacial lake size and dynamics, and local climatic variability. Yet whether and how these aspects affect GLOF hazards still awaits more quantitative support.

Previous work on GLOF susceptibility and hazard in the region focused on identifying or classifying potentially unstable glacial lakes, including local case studies largely informed by fieldwork, dam-breach models (Koike and Takenaka, 2012; Somos-Valenzuela et al., 2012, 2014), and basinwide assessments (Bolch et al., 2011; Mool et al., 2011; Rounce et al., 2016; Wang et al., 2011). GLOF hazard appraisals for the entire HKKHN, however, remain rare (Veh et al., 2020). Most basin-wide studies proposed qualitative to semi-quantitative decision schemes using selective lists of presumed GLOF predictors (Table 1; Rounce et al., 2016). Yet researchers have used subjective rules to choose these variables and associated thresholds, leading to diverging hazard estimates (Rounce et al., 2016). Expert knowledge has thus been essential in GLOF hazard appraisals despite an increasing amount of freely available climatic, topographic, and glaciological data. Statistical models can help to estimate the occurrence probability of GLOFs and thus reduce the inherent subjective bias (Emmer and Vilímek, 2013). For example, Wang et al. (2011) classified the outburst potential of moraine-dammed lakes on the southeastern Tibetan Plateau by applying a fuzzy consistent matrix method. They used as inputs the size of the parent glacier, the distance and slope between lake and glacier snout, and the mean steepness of the moraine dam and the glacier snout to come up with different nominal hazard categories. This and many similar qualitative ranking schemes are accessible to a broader audience and policy makers but are difficult to compare, and they potentially oversimplify uncertainties.

One way to deal with these uncertainties in a more objective way involves a Bayesian approach. Here we used this probabilistic reasoning with data-driven models. Specifically, we tested how well some of the more widely adopted predictors of GLOF susceptibility and hazard fare in a multi-level logistic regression that is informed more by data rather than by expert opinion. We checked how well this approach identifies glacial lakes in the HKKHN that had released GLOFs in the past four decades. Our method estimates the probability of correctly detecting historic GLOFs from a set of predictors which act as proxies subsuming various physical processes described as being relevant to GLOFs. Triggering mechanisms of these GLOFs are rarely reported, however. Thus, we discuss what more we can learn about how these historic GLOFs were linked to readily available measures of topography, monsoonality, and glaciological changes. Our model results provide a posterior probability of outburst conditioned on detection, and this may be used as a relative metric of GLOF release from a given lake. Therefore, our approach is an alternative to a formal assessment of moraine-dam stability, which is (geo-)technically feasible only at selected sites and at scales much finer than our regional and decadal focus.

\section{Study area, data, and methods}

\subsection{Study area and data}

We studied glacial lakes of the Hindu Kush-KarakoramHimalayas-Nyainqentanglha (HKKHN) region that we defined here as the Asian mountain ranges between 16 to $39^{\circ} \mathrm{N}$ and 61 to $105^{\circ} \mathrm{E}$, i.e. from Afghanistan to Myanmar (Fig. 1; Bajracharya and Shrestha, 2011). Following the outlines of glacier regions in High Mountain Asia used in the Randolph Glacier Inventory version 6.0 (RGI Consortium, 2017) and those defined by Brun et al. (2017), Veh et al. (2020) subdivided our study area into seven mountain ranges: the Hindu Kush, the Karakoram, the Western Himalaya, the Central Himalaya, the Eastern Himalaya, the Nyainqentanglha, and the Hengduan Shan. Meltwater from the HKKHN's extensive snow and ice cover, often referred to as the "Third Pole", feeds 10 major river systems to provide water for some 1.3 billion people (Molden et al., 
Table 1. Frequently used predictors of GLOF susceptibility and hazard in the HKKHN.

\begin{tabular}{|c|c|c|c|}
\hline $\begin{array}{l}\text { Predictor } \\
\text { groups }\end{array}$ & $\begin{array}{l}\text { GLOF susceptibility and } \\
\text { hazard predictors }\end{array}$ & $\begin{array}{l}\text { Tested in } \\
\text { this study }\end{array}$ & Reference \\
\hline \multirow{4}{*}{$\begin{array}{l}\text { Lake } \\
\text { characteristics } \\
\text { and dynamics }\end{array}$} & Glacial lake elevation & $\checkmark$ & Mergili and Schneider (2011) \\
\hline & Catchment area & $\checkmark$ & Allen et al. (2019); GAPHAZ (2017) \\
\hline & Glacial lake area & $\checkmark$ & $\begin{array}{l}\text { Aggarwal et al. (2016); Allen et al. (2019); Bolch et al. (2011); GAPHAZ (2017); Ives } \\
\text { et al. (2010); Khadka et al. (2021); Mergili and Schneider (2011); Prakash and Nagara- } \\
\text { jan (2017); Wang et al. (2012); Worni et al. (2013) }\end{array}$ \\
\hline & $\begin{array}{l}\text { Lake-area change (growth and } \\
\text { shrinkage, absolute change) }\end{array}$ & $\checkmark$ & $\begin{array}{l}\text { Aggarwal et al. (2016); Bolch et al. (2011); Ives et al. (2010); Khadka et al. (2021); } \\
\text { Mergili and Schneider (2011); Prakash and Nagarajan (2017); Rounce et al. (2016); } \\
\text { Wang et al. (2012) }\end{array}$ \\
\hline $\begin{array}{l}\text { Potential } \\
\text { downstream } \\
\text { impact }\end{array}$ & Lake volume & - & $\begin{array}{l}\text { Aggarwal et al. (2016); Bolch et al. (2011); GAPHAZ (2017); Kougkoulos et al. (2018); } \\
\text { Mergili and Schneider (2011) }\end{array}$ \\
\hline \multirow[t]{6}{*}{ Dam stability } & Moraine-wall steepness & - & $\begin{array}{l}\text { Allen et al. (2019); Bolch et al. (2011); Dubey and Goyal (2020); GAPHAZ (2017); } \\
\text { Ives et al. (2010); Khadka et al. (2021); Prakash and Nagarajan (2017); Rounce et al. } \\
\text { (2016); Wang et al. (2011); Worni et al. (2013) }\end{array}$ \\
\hline & Width-to-height ratio & - & $\begin{array}{l}\text { Aggarwal et al. (2016); Bolch et al. (2011); GAPHAZ (2017); Ives et al. (2010); Prakash } \\
\text { and Nagarajan (2017); Worni et al. (2013) }\end{array}$ \\
\hline & Lake freeboard & - & $\begin{array}{l}\text { Bolch et al. (2011); GAPHAZ (2017); Kougkoulos et al. (2018); Mergili and Schneider } \\
\text { (2011); Prakash and Nagarajan (2017); Worni et al. (2013) }\end{array}$ \\
\hline & Existence of a buried ice core & - & $\begin{array}{l}\text { Bolch et al. (2011); Dubey and Goyal (2020); GAPHAZ (2017); Ives et al. (2010); } \\
\text { Rounce et al. (2016) }\end{array}$ \\
\hline & Dam type & $\checkmark$ & $\begin{array}{l}\text { GAPHAZ (2017); Kougkoulos et al. (2018); Mergili and Schneider (2011); Wang et al. } \\
\text { (2011); Worni et al. (2013) }\end{array}$ \\
\hline & Moraine lithology & - & GAPHAZ (2017) \\
\hline \multirow{8}{*}{$\begin{array}{l}\text { Potential } \\
\text { triggering } \\
\text { mechanisms } \\
\text { (geomorphic) }\end{array}$} & Seismic activity & - & $\begin{array}{l}\text { GAPHAZ (2017); Ives et al. (2010); Kougkoulos et al. (2018); Mergili and Schneider } \\
\text { (2011); Prakash and Nagarajan (2017) }\end{array}$ \\
\hline & $\begin{array}{l}\text { Distance from parent glacier } \\
\text { snout }\end{array}$ & - & $\begin{array}{l}\text { Aggarwal et al. (2016); Ives et al. (2010); Khadka et al. (2021); Kougkoulos et al. } \\
\text { (2018); Prakash and Nagarajan (2017); Wang et al. (2011, 2012); Worni et al. (2013) }\end{array}$ \\
\hline & Steepness parent glacier snout & - & $\begin{array}{l}\text { Bolch et al. (2011); Ives et al. (2010); Kougkoulos et al. (2018); Prakash and Nagarajan } \\
\text { (2017); Wang et al. (2011) }\end{array}$ \\
\hline & $\begin{array}{l}\text { Parent glacier calving potential } \\
\text { (width, crevasse density) }\end{array}$ & - & GAPHAZ (2017); Ives et al. (2010); Mergili and Schneider (2011) \\
\hline & $\begin{array}{l}\text { Regional or parent glacier-mass } \\
\text { balance }\end{array}$ & $\checkmark$ & Bolch et al. (2011); Ives et al. (2010) \\
\hline & $\begin{array}{l}\text { Mass movements (traces, tra- } \\
\text { jectories, probabilities) }\end{array}$ & - & $\begin{array}{l}\text { Allen et al. (2019); Bolch et al. (2011); Dubey and Goyal (2020); GAPHAZ (2017); } \\
\text { Ives et al. (2010); Khadka et al. (2021); Mergili and Schneider (2011); Prakash and } \\
\text { Nagarajan (2017); Rounce et al. (2016); Worni et al. (2013) }\end{array}$ \\
\hline & Permafrost conditions & - & GAPHAZ, 2017 \\
\hline & $\begin{array}{l}\text { Upstream lake (with GLOF po- } \\
\text { tential) }\end{array}$ & - & Dubey and Goyal (2020); GAPHAZ (2017); Khadka et al. (2021) \\
\hline \multirow{7}{*}{$\begin{array}{l}\text { Potential } \\
\text { triggering } \\
\text { events } \\
\text { (climatic) }\end{array}$} & Annual mean temperature & - & GAPHAZ (2017); Liu et al. (2014); Wang et al. (2008) \\
\hline & Temperature seasonality & - & Ives et al. (2010); Kougkoulos et al. (2018) \\
\hline & $\begin{array}{l}\text { Temperature extremes (inten- } \\
\text { sity, frequency) }\end{array}$ & - & GAPHAZ (2017) \\
\hline & Annual precipitation & - & Wang et al. $(2008,2012)$ \\
\hline & Precipitation seasonality & - & Ives et al. (2010); Kougkoulos et al. (2018) \\
\hline & $\begin{array}{l}\text { Precipitation extremes (inten- } \\
\text { sity, frequency) }\end{array}$ & - & GAPHAZ (2017); Prakash and Nagarajan (2017) \\
\hline & $\begin{array}{l}\text { Summer precipitation or proxy } \\
\text { of monsoonality }\end{array}$ & $\checkmark$ & Wang et al. $(2008,2012)$ \\
\hline
\end{tabular}




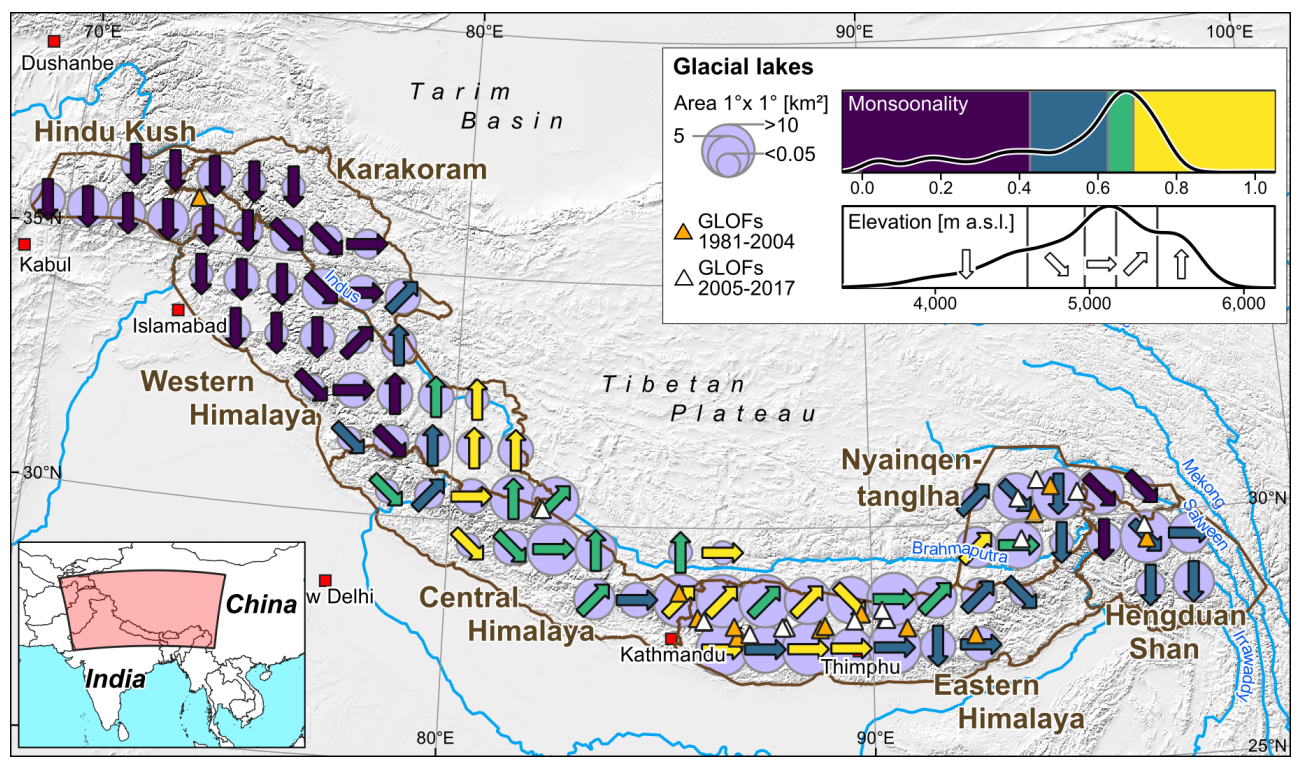

Figure 1. Overview map of the HKKHN showing the distribution of moraine-dammed lakes in $1^{\circ} \times 1^{\circ}$ bins (blue bubbles scaled by area), their elevation (expressed as quantiles coded by arrows; see inset for elevation distribution), and average monsoonality (colour coded; see inset for monsoonality distribution), defined here as the fraction of total annual precipitation falling in the summer months. Orange and white triangles indicate reported moraine-dam failures before and after 2005, respectively (Veh et al., 2019). Background hillshade is from the GTOPO30 global 30 arcsec elevation dataset (https://doi.org/10.5066/F7DF6PQS).

2014). There, glaciers have had an overall negative mass balance historically and lost $150 \pm 110 \mathrm{~kg} \mathrm{~m}^{-2} \mathrm{yr}^{-1}$ on average from 2006 to 2015, though with balanced trends in the Karakoram (Bolch et al., 2019; Hock et al., 2019). Since the 1970s, some Karakoram glaciers also accelerated in flow, whereas glaciers stalled elsewhere in the HKKHN (Dehecq et al., 2019). In the RCP8.5 scenario the HKKHN glaciers could lose $64 \pm 5 \%$ of their total mass by 2100 compared to estimated glacier volumes for the interval 1995 to 2015 (Kraaijenbrink et al., 2017). How much of this melting of glaciers is due to EDW remains under debate (Palazzi et al., 2017; Rangwala and Miller, 2012; Tudoroiu et al., 2016). Snowfall at lower elevations is also likely to decrease (Hock et al., 2019; Terzago et al., 2014), judging from snowfall and glacier-mass balances of past decades (Kapnick et al., 2014; King et al., 2019). Monsoon precipitation is likely to become more episodic and intensive (Palazzi et al., 2013).

Guided by these projections, we selected several widely used glacial lake susceptibility predictors (Table 2 ).

We used lake elevation $z$ (ma.s.l.) as a proxy for the standard lapse rate of tropospheric air temperature (Rolland, 2003; Yang and Smith, 1985). This elevation-dependent thermal gradient is also a major control on the distribution of alpine permafrost (Etzelmüller and Frauenfelder, 2009) and precipitation. Mean annual rainfall along the Himalayan front can exceed $4000 \mathrm{~mm}$ at elevations some $4000 \mathrm{~m}$ high, where $\sim 25 \%$ of all glacial lakes occur (Fig. 1; Bookhagen and Burbank, 2010). Lake elevation should also represent first-order topographic effects of EDW. For example, the sta- bility of low-lying moraine dams may be compromised by the loss of permafrost and commensurate increases in permeability in the moraine barrier and adjacent valley slopes (Haeberli et al., 2017).

Glacial lake area $A\left(\mathrm{~m}^{2}\right)$ and its rate of change $\Delta A$ (net change) and $A^{*}$ (relative change, $\%$ ) are other common predictors of susceptibility and hazard in GLOF studies (Allen et al., 2019; Bolch et al., 2011; Prakash and Nagarajan, 2017; see Table 1 for full list of references) that we considered here. Due to a general lack of available bathymetric data on a regional scale, a number of studies used the frequently observed phenomenon that lake area scales with lake volume and depth (Huggel et al., 2002; Iribarren Anacona et al., 2014). Growing lake depths increase the hydrostatic pressure acting on moraine dams, thus raising the potential of failure (Iribarren Anacona et al., 2014; Rounce et al., 2016). In the past decades, lake areas have grown largest in the Central Himalayas (+23\% in 1990-2015; Nie et al., 2017) and Nyainqentanglha Mountains but lowest in the northwestern Himalayas (Chen et al., 2021; Nie et al., 2017), and many studies have emphasised the role of growing lakes on GLOF susceptibility (e.g. GAPHAZ, 2017; Prakash and Nagarajan, 2017; Rounce et al., 2016). Many previous GLOF assessment schemes included lake area or lake-area growth as a proxy for the volume of water that could be potentially released by an outburst and thus the resulting downstream hazard (e.g. Allen et al., 2019; Bolch et al., 2011). However, a number of studies also stress that lake area and its growth define the exposure to external and internal triggers of moraine dam breach: larger 
Table 2. Details on tested predictors and our reasoning for selection based on their commonly reported physical links to GLOF susceptibility.

\begin{tabular}{|c|c|c|c|c|c|}
\hline $\begin{array}{l}\text { GLOF susceptibility } \\
\text { predictor }\end{array}$ & \multicolumn{2}{|c|}{ Symbol } & Unit & Data source & Selection reasoning \\
\hline Glacial lake elevation & \multicolumn{2}{|l|}{$z$} & ma.s.l. & SRTM DEM & $\begin{array}{l}\text { - strong link between elevation and temperature at high al- } \\
\text { titudes (standard lapse rate of tropospheric air temperature) } \\
\rightarrow \text { elevation dependence of permafrost and precipitation } \\
\text { patterns }\end{array}$ \\
\hline Catchment area & \multicolumn{2}{|l|}{$C$} & $\mathrm{~m}^{2}$ & SRTM DEM & $\begin{array}{l}\text { - potential for surface runoff into lake from precipitation } \\
\text { and snow melt }\end{array}$ \\
\hline Glacial lake area & $A$ & & $\mathrm{~m}^{2}$ & SRTM DEM & $\begin{array}{l}\text { - proxy for lake volume and depth and thus hydrostatic } \\
\text { pressure acting on moraine dam }\end{array}$ \\
\hline \multirow[t]{4}{*}{ Lake-area change } & $\Delta A$ & Net change & - & \multirow[t]{4}{*}{ Wang et al. (2020) } & \multirow{4}{*}{$\begin{array}{l}\text { - increasing lake area commonly reported as scaling with } \\
\text { increasing lake depth } \\
\rightarrow \text { potentially increased hydrostatic pressure acting on the } \\
\text { moraine dam } \\
\text { - increased proximity to steep valley slopes } \\
\rightarrow \text { increased potential of mass movements entering the lake }\end{array}$} \\
\hline & \multirow[t]{3}{*}{$A^{*}$} & $\begin{array}{l}\text { Relative change } \\
\text { (between) }\end{array}$ & \multirow[t]{3}{*}{$\%$} & & \\
\hline & & $A^{* a}(1990-2005)$ & & & \\
\hline & & $\begin{array}{l}A^{* b}(2005-2018) \\
A^{* c}(1990-2018)\end{array}$ & & & \\
\hline \multirow[t]{2}{*}{ Glacier-mass balance } & $r$ & $\begin{array}{l}\text { Glacier-mass balance } \\
\text { region }\end{array}$ & - & \multirow[t]{2}{*}{ Brun et al. (2017) } & \multirow{2}{*}{$\begin{array}{l}\text { - proxy for direct or surface runoff glacier meltwater input, } \\
\text { calving potential of parent glacier front, and permafrost dis- } \\
\text { tribution in lake surroundings } \\
\text { - link between regional glacier-mass balance and synoptic } \\
\text { regime (winter westerlies vs. monsoon dominated) }\end{array}$} \\
\hline & $\Delta m_{\mathrm{r}}$ & $\begin{array}{l}\text { Average glacier-mass } \\
\text { balance }\end{array}$ & mw.e. $\mathrm{yr}^{-1}$ & & \\
\hline $\begin{array}{l}\text { Monsoonality } \\
\text { (annual proportion of } \\
\text { summer precipitation) }\end{array}$ & $M$ & & $\%(\mathrm{~mm})$ & $\begin{array}{l}\text { CHELSA } \\
\text { (Karger et al., } \\
\text { 2017) }\end{array}$ & $\begin{array}{l}\text { - high-intensity precipitation events during monsoon season } \\
\text { potentially leading to increased surface runoff into glacial } \\
\text { lakes (cloudburst event) } \\
\text { - seasonal increases in lake levels and, hence, lake depths } \\
\text { increasing hydrostatic pressure acting on moraine dam } \\
\text { - link between regional glacier-mass balance and synoptic } \\
\text { regime (winter westerlies vs. monsoon dominated) }\end{array}$ \\
\hline
\end{tabular}

and growing lakes offer more area for impacts from mass flows such as avalanches, rockfalls, and landslides originating from adjacent valley slopes (GAPHAZ, 2017; Haeberli et al., 2017; Prakash and Nagarajan, 2017; Rounce et al., 2016). Some authors also link growing lake areas to an increase in hydrostatic pressure acting on its moraine dam, thus making the latter more susceptible to sudden failure (Iribarren Anacona et al., 2014; Mergili and Schneider, 2011).

We also tested the impact of upstream catchment area $C$ $\left(\mathrm{m}^{2}\right)$ on GLOF susceptibility. A larger upstream catchment area has been associated with an increased susceptibility to GLOFs as runoff from intense precipitation, as well as glacier and snow melt, can lead to sudden increases in lake volume (Allen et al., 2019; GAPHAZ, 2017). We find that catchment area $C$ correlates with lake area $A$ (Pearson's $\rho=0.45)$. We thus preferred $C$ over $A$ in two of our models as $C$ is invariant at the timescale of our study, and we use these two models to explicitly test whether runoff by glacier melt or monsoonal precipitation had an effect on GLOFs in our study area.

Similar to changes in lake area, glacier dynamics are frequently mentioned though rarely incorporated quantitatively in susceptibility appraisals (Bolch et al., 2011; Ives et al., 2010). This motivated us to consider the average changes in regional glacier-mass balances between 2000 and 2016
$\Delta m$ (m water equivalent $\mathrm{yr}^{-1}$ ) from Brun et al. (2017). These readily available data on regional glacier-mass balances are proxies for other, less accessible physical controls on GLOF susceptibility such as glacial meltwater input, either directly from the parent glacier or from glaciers upstream, as well as permafrost decay in slopes fringing the lake (see Table 2 for full list).

Meteorological drivers entered previous qualitative GLOF hazard appraisals mostly as (the probability of) extreme monsoonal precipitation events: the Kedarnath GLOF disaster, for example, was triggered by intense surface runoff (Huggel et al., 2004; Prakash and Nagarajan, 2017). Heavy rainfall may also trigger landslides or debris flows from adjacent hillslopes followed by displacement waves that overtop moraine dams (Huggel et al., 2004; Prakash and Nagarajan, 2017). Elevated lake levels during the monsoon season also raise the hydrostatic pressure acting on moraine dams (Richardson and Reynolds, 2000). Furthermore, different precipitation regimes and climatic preconditions may also influence moraine-dam failure mechanics (Wang et al., 2012). Intense precipitation occurs in our study region largely during the summer monsoon, so we derived a synoptic measure of monsoonality $M(\%)$. We define monsoonality $M$ in terms of the annual proportion of summer, i.e. the warmest quarter, precipitation, which is highest in the southeast HKKHN, where 
it is linked to monsoonal low-pressure systems (Krishnan et al., 2019).

We extracted information on these characteristics for glacial lakes recorded in two inventories. First, we used the ICIMOD database of 25614 lakes manually mapped from Landsat imagery acquired in $2005 \pm 2$ years (Maharjan et al., 2018), from which we extracted 7284 lakes dammed by moraines (classes $\mathrm{m}(\mathrm{l}), \mathrm{m}(\mathrm{e})$, and $\mathrm{m}(\mathrm{o})$ in Maharjan et al., 2018). Second, we identified from an independent regional GLOF inventory (Veh et al. 2019) 31 lakes that had at least one outburst between 1981 and 2017 and that are listed in the ICIMOD inventory. The triggering mechanism of these studied GLOFs is reported in only seven cases, four of which are attributed to ice avalanches entering the lake (e.g. Tam Pokhari, Nepal, and Kongyangmi La Tsho, India; Ives et al., 2010; Nie et al., 2018). Other triggers of the GLOFs studied here include piping (Yindapu Co, China; Nie et al., 2018) and the collapse of an ice-cored moraine (Luggye Tsho, Bhutan; Fujita et al., 2008). We focused on lakes $>10000 \mathrm{~m}^{2}$ to ensure comparability between the two inventories, thus acquiring a final sample size of 3390 lakes. Given the sparse network of weather stations in the HKKHN, we computed the monsoonality averaged for each lake from the $1 \mathrm{~km}$ resolution CHELSA bioclimatic variables (Karger et al., 2017). These variables are correlated with elevation because of the same underlying interpolation technique, so we limited our models to those with poorly correlated predictors. This meant omitting other predictors such as mean annual temperature, annual precipitation totals, and annual temperature and precipitation variability. We extracted topographic data from the void-free $30 \mathrm{~m}$ resolution SRTM (Shuttle Radar Topographic Mission of 2000) digital elevation model (DEM) and use approximate lake-area changes for two intervals (1990 to 2005 and 2005 to 2018) by Wang et al. (2020). We discarded newer, higher-resolved DEMs to minimise data gaps and artefacts. Overall, we considered six topographic, synoptic, and glaciological predictors (Fig. 2, Table 2).

\subsection{Bayesian multi-level logistic regression}

We used logistic regression to learn the probability of whether a given lake in the HKKHN had a reported GLOF in the past four decades. This method was pioneered for moraine-dammed lakes in British Columbia, Canada (McKillop and Clague, 2007). Logistic regression estimates a binary outcome $y$ from the optimal linear combination of $p$ weighted predictors $x=\left\{x_{1}, \ldots, x_{\mathrm{p}}\right\}$. The probability $y=P_{\mathrm{GLOF}}$ that lake $i$ had released a GLOF is expressed as follows:

$y_{i} \sim \operatorname{Bernoulli}\left(\mu_{i}\right)$,

$\mu_{i}=S\left(\alpha_{0}+\beta_{1} x_{i, 1}+\beta_{2} x_{i, 2}+\ldots+\beta_{\mathrm{p}} x_{i, \mathrm{p}}\right)$,

where

$S(x)=\frac{1}{1+\exp (-x)}$.
Here $\alpha_{0}$ is the intercept, and $\beta=\left\{\beta_{1}, \ldots, \beta_{\mathrm{p}}^{T}\right\}$ are the $p$ predictor weights (Gelman and Hill, 2007). The logit function $S^{-1}(x)$ describes the odds on a logarithmic scale (the logodds ratio) such that a unit increase in predictor $x_{\mathrm{m}}$ raises the log-odds ratio by an amount of $\beta_{\mathrm{m}}$, with all other predictors fixed. We used standardised data to ensure that the weights measure the relative contributions of their predictors to the classification, whereas the intercept expresses the base case for average predictor values.

Our strategy was to explore commonly reported predictors of GLOF susceptibility and dam stability as candidate predictors (Fig. 2, Tables 1 and 2). We further acknowledged that data on moraine-dammed lakes in the HKKHN are structured, reflecting, for example, the variance in topography and synoptic regime such as the summer monsoon in the eastern HKKHN and westerlies in the western HKKHN. Different data sources, collection methods, and resolutions also add structure. This structure is routinely acknowledged, often raised as a caveat, but rarely treated in GLOF studies. Ignoring such structure can lead to incorrect inference by bloating the statistical significance of irrelevant or inappropriate model parameter estimates (Austin et al., 2003). To explicitly address this issue, we chose a multi-level logistic regression as a compromise between a single pooled model and individual models for each group in the data (Fig. 3; Gelman and Hill, 2007; Shor et al., 2007).

We recast Eq. (2) using a group index $j$ :

$$
\begin{aligned}
\mu_{i} & =S\left(\alpha_{j}+\beta_{1} x_{i, 1}+\beta_{2} x_{i, 2}+\ldots+\beta_{\mathrm{p}} x_{i, \mathrm{p}}\right), \\
\alpha_{j} & \sim N\left(\mu_{\alpha} \sigma_{\alpha}\right),
\end{aligned}
$$

where $\mu_{\alpha}$ is the mean, and $\sigma_{\alpha}$ is the standard deviation of the group-level intercepts $\alpha_{j}$ that are learned from all data and inform each other via the model hierarchy. We used a Bayesian framework (Kruschke and Liddell, 2018) by combining the likelihood of observing the data with prior knowledge from previous GLOF studies (Fischer et al., 2020). The small number of reported GLOFs introduces strong imbalance to our data given that some regions, and hence levels, had few or no reported GLOFs. Although this would be problematic in most other modelling approaches, Bayesian multi-level models are well suited for this kind of imbalanced training data (Gelman and Hill, 2007; Shor et al., 2007; Stegmueller, 2013).

We used the statistical programming language $\mathrm{R}$ with the package brms, which estimates joint posterior distributions using a Hamiltonian Monte Carlo algorithm and a No-UTurn Sampler (NUTS; Bürkner, 2017). We ran four chains of 1500 samples after 500 warm-up runs each and checked for numerical divergences or other pathological issues. We only considered models with all values of $\hat{R}<1.01-$ a measure of numerical convergence of sampling chains - to avoid unbiased posterior distributions (Nalborczyk et al., 2019).

Unless stated otherwise, we used a weakly informative half Student's $t$ distribution with three degrees of freedom 

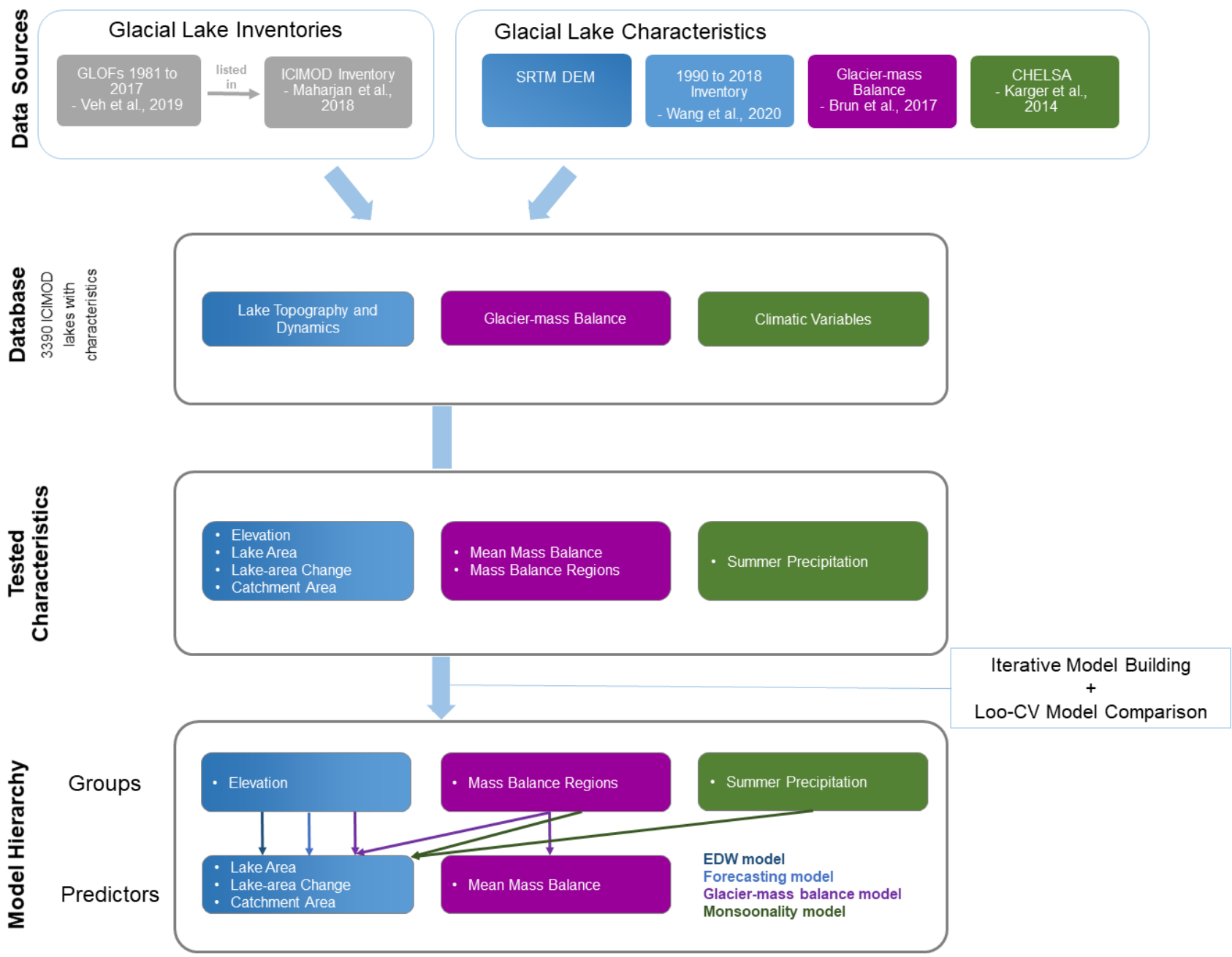

Figure 2. Data sources and workflow; EDW = elevation-dependent warming.

Table 3. Prior distributions for group- and population-level effects.

\begin{tabular}{lll}
\hline Level & Model coefficient & Probability density function \\
\hline Group-level effects & Standard deviation $\sigma$ of group model variables & $\sigma_{\alpha} \sim \operatorname{HalfStudentT}(3,10)$ \\
\hline Population-level effects & Intercept & $\alpha_{j} \sim \operatorname{Cauchy}(0,2.5)$ \\
& Weight of predictors with weak prior knowledge & $\beta_{\mathrm{p}} \sim \operatorname{Cauchy}(0,2.5)$ \\
& Weight of predictor lake area $\beta_{A}$ & $\beta_{A} \sim \operatorname{Normal}(1,2)$ \\
\hline
\end{tabular}

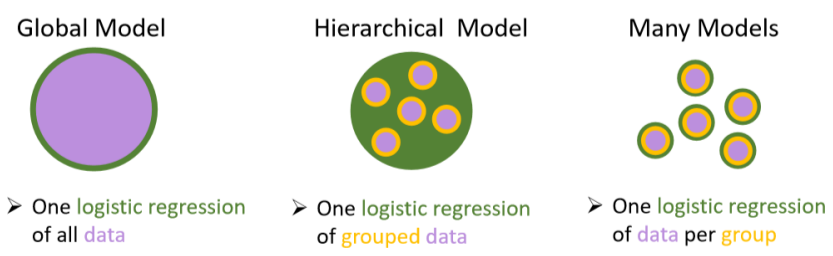

Figure 3. Schematic comparison of global vs. multi-level logistic regression models. and a scale parameter of 10 for the standard deviations of group-level effects (Table 3; Bürkner, 2017; Gelman, 2006). At the population level, we chose weakly informative priors for the intercept and coefficients for which we had no other prior knowledge. We encoded this lack of knowledge with a prior Cauchy distribution centred at zero and with a scale of 2.5, following the recommendation of Gelman et al. (2008). Rapidly growing moraine-dammed lakes are a widely used predictor of high GLOF susceptibility (e.g. GAPHAZ, 2017; Prakash and Nagarajan, 2017; Rounce et 
al., 2016). We encoded this notion in a prior Gaussian distribution with 1 unit mean and standard deviation, hence shifting more probability mass towards positive regression weights without excluding the possibility of negative weight estimates (Table 3).

We estimated the predictive performance of all models with leave-one-out (LOO) cross-validation as part of the brms package (Bürkner, 2017). LOO values like the expected $\log$ predictive density (ELPD) summarise the predictive error of Bayesian models similar to the Akaike information criterion or related metrics of model selection (Vehtari et al., 2017). They are based on the log-likelihood of the posterior simulations of parameter values (Vehtari et al., 2017).

\section{Results}

\subsection{Elevation-dependent warming model}

Our first model addresses the notion of elevation-dependent warming (EDW) by considering lake elevation as a grouping structure in the data. The model further assumes that the GLOF history of a given lake is a function of its area $A$ and net change $\Delta A$. This dependence differs by up to a constant, i.e. the varying model intercept, across elevation bands $z$ that we define here in five quantile grouping levels (Fig. 1). The model intercept may vary across these elevation bands, whereas lake area (in 2005) and its net change remain fixed predictors. In essence, this varying-intercept model acknowledges that glacial lakes in the same elevation band may have had a common baseline susceptibility to GLOFs in the past four decades. The indicator variable $\Delta A$ records whether a given lake had a net growth or shrinkage between 1990 and 2018:

$\mu_{i}=S\left(\alpha_{z}+\beta_{A} A_{i}+\beta_{\Delta A} \Delta A_{i}\right)$,

$\alpha_{z} \sim N\left(\mu_{z} \sigma_{z}\right)$,

where index $z$ identifies the elevation band.

We obtain posterior estimates of $\beta_{A}=0.79^{+0.27} /-0.27$ and $\beta_{\triangle A}=0.48^{+0.73} /-0.72$ (95\% highest density interval, HDI) which indicate that larger lakes are more likely classified as having had a GLOF, whereas net growth or shrinkage has ambivalent weight as its HDI includes zero (Figs. 4 and 5, Table 4). On the population level, the low spread of intercepts $\left(\sigma_{z}=0.29^{+0.68} /-0.28\right)$ estimated for each of the five elevation bands shows that elevation effects modulate the pooled model only minutely. These posterior effects are positive for the lower elevation bands but negative for the higher elevation bands. Thus, the mean posterior probability of a GLOF history, $P_{\mathrm{GLOF}}$, under this model increases slightly for lakes in lower elevations and with a larger surface area in 2005. We also observe that $P_{\mathrm{GLOF}}$ is less than 0.5 regardless of reported lake elevation and that the associated uncertainties are higher for larger lakes.

\subsection{Forecasting model}

Our second model refines our approach by including only relative changes in lake area before the reported GLOFs happened. We can use this model to fore- or hindcast historic GLOFs in our inventory. Here we use lake area $A$ (in 2005) and its relative change $A^{* a}$ from 1990 to 2005 as predictors of 11 GLOFs that occurred between 2005 and 2018 across the five elevation bands. We assume that larger and deeper lakes are more robust to relative size changes and thus also include a multiplicative interaction term between lake area and its change:

$\mu_{i}=S\left(\alpha_{z}+\beta_{A} A_{i}+\beta_{A^{* a}} A_{i}^{* a}+\beta_{A \times A^{* a}} A_{i} \cdot A_{i}^{* a}\right)$.

We find that lake area has a credible positive posterior weight of $\beta_{A}=0.86^{+0.44} /-0.43$; hence greater lakes are more likely to have had a GLOF between 2005 and 2018. The weight of relative lake-area change in the 15 years before is ambiguous $\left(\beta_{A^{* a}}=-0.04^{+0.76} /-0.67\right)$ and so is the interaction $\left(\beta_{A \cdot A^{* a}}=-0.16^{+0.41} /-0.51\right)$. On average, however, relative increases in lake area between 1990 and 2005 slightly decrease $P_{\mathrm{GLOF}}$. Unlike in the elevation-dependent warming model, the effects of elevation bands are less clear, while the uncertainties are more pronounced and highest for larger and shrinking lakes (Figs. 4 and 6).

\subsection{Glacier-mass balance model}

Besides elevation, our third model considers the average historic glacier-mass balances across the HKKHN. The model assumes that mean ice losses $\Delta m$ add a distinctly regional structure to the susceptibility to GLOFs in the past four decades given that accelerated glacier melt may raise GLOF potential (Emmer, 2017; Richardson and Reynolds, 2000). We use our seven study area regions as group levels $r$ and their average glacier-mass balance, derived from Brun et al. (2017), as a group-level predictor $\Delta m_{\mathrm{r}}$. Our pooled predictors are the relative change in lake area $A^{* b}$ from 2005 to 2018 (to ensure a comparable time interval) and the catchment area $C$ upstream of each lake. We replace lake area by its upstream catchment area, which is less prone to change but well correlated to lake area.

$\mu_{i}=S\left(\alpha_{z}+\alpha_{\mathrm{r}}+\beta_{A^{* b}} A_{i}^{* b}+\beta_{C} C_{i}\right)$,

$\alpha_{\mathrm{r}} \sim N\left(\mu_{\mathrm{r}}+\gamma_{\mathrm{r}} \Delta m_{\mathrm{r}} \sigma_{\mathrm{r}}\right)$.

This model returns a positive weight for catchment area $\left(\beta_{C}=0.85^{+0.50} /-0.50\right)$ and a negative weight for relative lake-area changes $\left(\beta_{A^{* b}}=-0.69^{+0.64} /-0.61\right)$, whereas the effect of the mean glacier-mass balance remains inconclusive $\left(\gamma_{\mathrm{r}}=-2.98^{+4.87} /-6.70\right)$. On the basis of higher standard deviations, we learn that effects of glaciological regions vary more than those of elevation bands $\left(\sigma_{\mathrm{r}}=0.81^{+1.60} /-0.78\right.$ and 

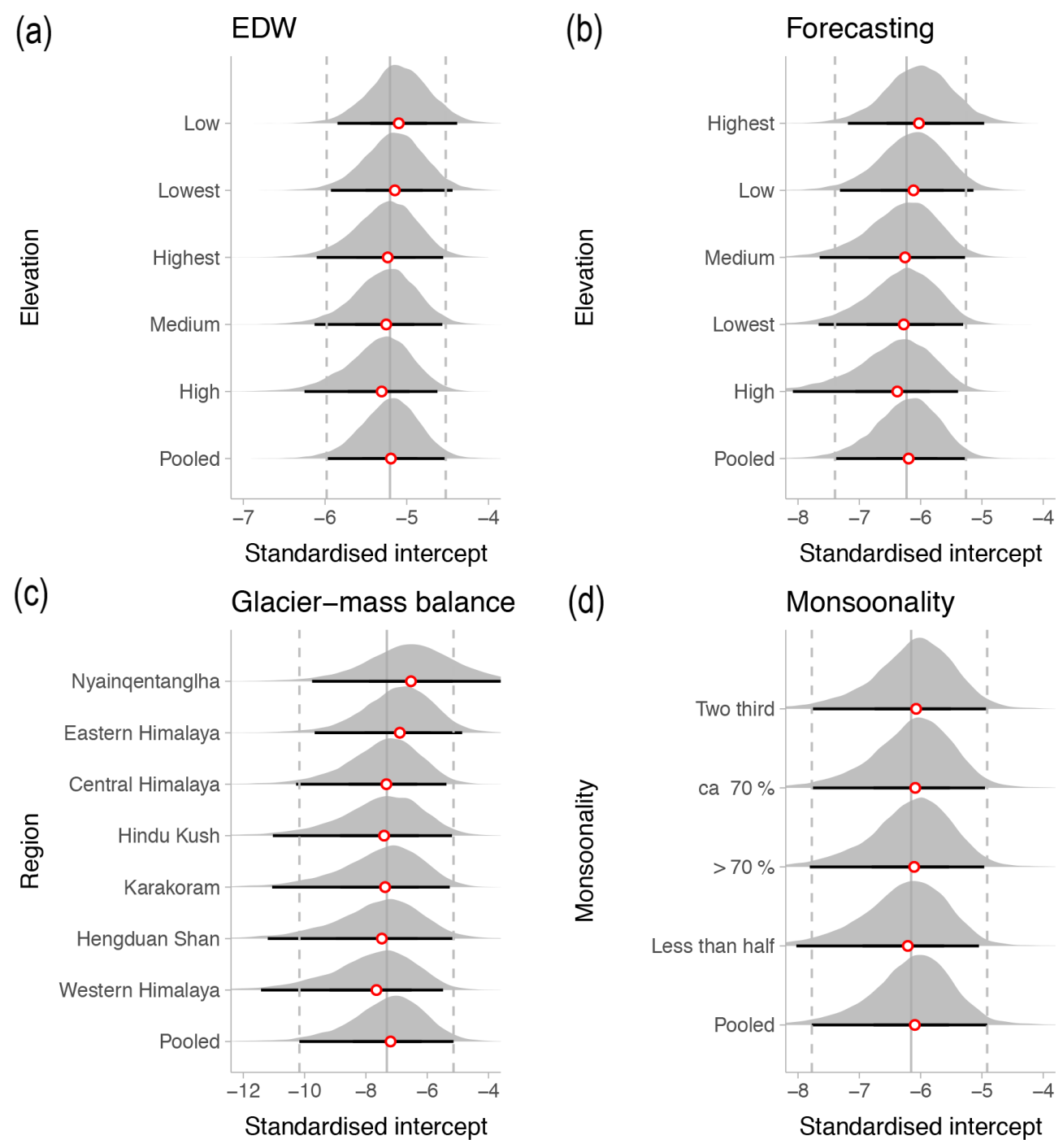

Figure 4. Posterior pooled and group-level intercepts for the four models considered. EDW = elevation-dependent warming. See Fig. 1 for a summary of the quantiles of elevation and monsoonality. Horizontal black lines delimit $95 \%$ HDI, and red circles indicate posterior medians. Vertical continuous (dashed) grey lines are posterior means (95\% HDI) of the pooled intercept of each model. Intercepts are standardised and thus refer to lakes with average predictor values.

$\left.\sigma_{z}=0.48^{+1.19} /-0.47\right)$. When training this model on a subset of glacial lakes with documented GLOFs that happened after 2000 (i.e. including only those in the interval covered by glacier-mass balance data), posterior estimates of $\sigma_{\mathrm{r}}$ increase to $1.11^{+1.77 /-1.03}$, further underlining our result that glacier-mass balance credibly affects $P_{\mathrm{GLOF}}$. This is also reflected in the posterior distributions across the glacier-mass balance regions (Fig. 4), as well as the calculated group-level effects. This model has the highest values of $P_{\mathrm{GLOF}}$ for average lakes (i.e. all average predictor values combined) in the Nyainqentanglha Mountains and the Eastern Himalaya (Fig. 4). In contrast to the forecasting model, we observe that increases in lake area now credibly depress $P_{\mathrm{GLOF}}$ (Fig. 7).

\subsection{Monsoonality model}

Our last model explores a synoptic influence on GLOF susceptibility by grouping the data by the summer proportion of mean annual precipitation and thus by approximate monsoonal contribution. We defined five monsoonality levels based on quantiles of the annual proportions of summer precipitation (Fig. 1). We use relative lake-area change $A^{* c}$ between 1990 and 2018 and catchment area $C$ as populationlevel predictors, as well as the additional grouping by regional glacier-mass balance:

$$
\begin{aligned}
& \mu_{i}=S\left(\alpha_{M}+\alpha_{\mathrm{r}}+\beta_{A^{* c}} A_{i}^{* c}+\beta_{C} C_{i}\right), \\
& \alpha_{M} \sim N\left(\mu_{M} \sigma_{M}\right),
\end{aligned}
$$



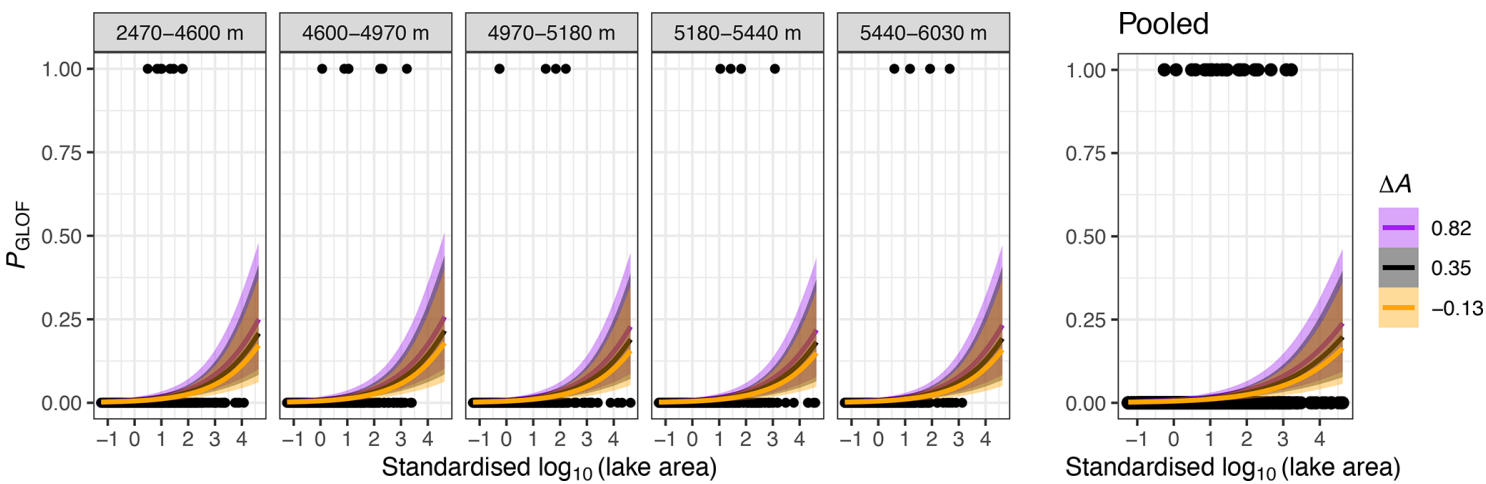

Figure 5. Elevation-dependent warming model: posterior probabilities $P_{\mathrm{GLOF}}$ as a function of standardised lake area $A$ (in 2005 ) and the sign of standardised lake-area change $\Delta A$ (i.e. net growth or shrinkage), grouped by quantiles of elevation (defined in Fig. 1; lowest: 2470-4600 m a.s.1.; low: 4600-4970 m a.s.1.; medium: 4970-5180 m a.s.1.; high: 5180-5440 m a.s.1.; highest: 5440-6030 m a.s.1.). Black dots are lake data with $\left(P_{\mathrm{GLOF}}=1\right)$ or without $\left(P_{\mathrm{GLOF}}=0\right)$ reported GLOF records. Thick coloured lines are mean fits, and colour shades encompass the associated $95 \%$ HDIs.

Table 4. Summary of the results of our four models. $\mathrm{CI}=$ credible interval.

\begin{tabular}{llrrrr}
\hline Model & Model parameter & Estimate & $\begin{array}{r}\text { Estimation } \\
\text { error }\end{array}$ & $\begin{array}{r}\text { Lower 95 \% CI } \\
\text { boundary }\end{array}$ & $\begin{array}{r}\text { Upper 95\% CI } \\
\text { boundary }\end{array}$ \\
\hline Elevation-dependent & $\alpha_{z}$ & -5.22 & 0.36 & -5.96 & -4.56 \\
warming model & $\beta_{A}$ & 0.79 & 0.14 & 0.52 & 1.06 \\
& $\beta_{\Delta A(1990 \text { to 2018) }}$ & 0.49 & 0.38 & -0.28 & 1.24 \\
& $\sigma_{z}$ & 0.28 & 0.27 & 0.01 & 0.99 \\
\hline Forecasting model & $\alpha_{z}$ & -6.23 & 0.54 & -7.39 & -5.26 \\
& $\beta_{A}$ & 0.87 & 0.22 & 0.44 & 1.31 \\
& $\beta_{A^{* a}(1990 \text { to } 2005)}$ & -0.04 & 0.38 & -0.71 & 0.73 \\
& $\beta_{A \cdot A^{* a}}$ & -0.16 & 0.24 & -0.67 & 0.26 \\
& $\sigma_{z}$ & 0.43 & 0.41 & 0.01 & 1.49 \\
\hline Glacier-mass & $\alpha_{z, r}$ & -7.31 & 1.26 & -10.15 & -5.19 \\
balance model & $\beta_{A^{* b}(2005 \text { to } 2018)}$ & -0.69 & 0.32 & -1.31 & -0.06 \\
& $\beta_{C}$ & 0.85 & 0.26 & 0.35 & 1.36 \\
& $\gamma_{\mathrm{r}}$ & -2.90 & 2.80 & -9.27 & 1.80 \\
& $\sigma_{z}$ & 0.47 & 0.44 & 0.01 & 1.61 \\
& $\sigma_{\mathrm{r}}$ & 0.83 & 0.66 & 0.03 & 2.47 \\
\hline Monsoonality & $\alpha_{M, r}$ & -6.14 & 0.70 & -7.70 & -4.91 \\
model & $\beta_{A^{* c}(1990 \text { to } 2018)}$ & -0.63 & 0.31 & -1.23 & -0.02 \\
& $\beta_{C}$ & 0.82 & 0.24 & 0.34 & 1.28 \\
& $\sigma_{M}$ & 0.40 & 0.42 & 0.01 & 1.49 \\
& $\sigma_{\mathrm{r}}$ & 0.78 & 0.62 & 0.03 & 2.31 \\
\hline & & & &
\end{tabular}

where index $M$ identifies the monsoonality group. We find that larger catchment areas $\left(\beta_{C}=0.82^{+0.46} /-0.48\right)$ and lakes with relative shrinkage $\left(\beta_{A^{* c}}=-0.63^{+0.59} /-0.59\right)$ credibly raise $P_{\mathrm{GLOF}}$ (Figs. 4 and 8 ). Higher standard deviations show that regional effects vary more for the mean glacialmass balance than for monsoonality $\left(\sigma_{\mathrm{r}}=0.79^{+1.59} /-0.76\right.$ and $\sigma_{M}=0.40^{+1.04} /-0.39$ ), although both hardly change the pooled model trend.

\subsection{Model performance and validation}

We estimate the performance of our models in terms of the posterior improvement of our prior chance of finding a lake with known outburst in the past four decades in our inventory by pure chance. We compare the posterior predictive mean $P_{\mathrm{GLOF}}$ with a mean prior probability that we estimate from the $\sim 1 \%$ proportion of lakes with known GLOFs in our training data. We measure what we have learned from each model in terms of the log-odds ratio that readily trans- 

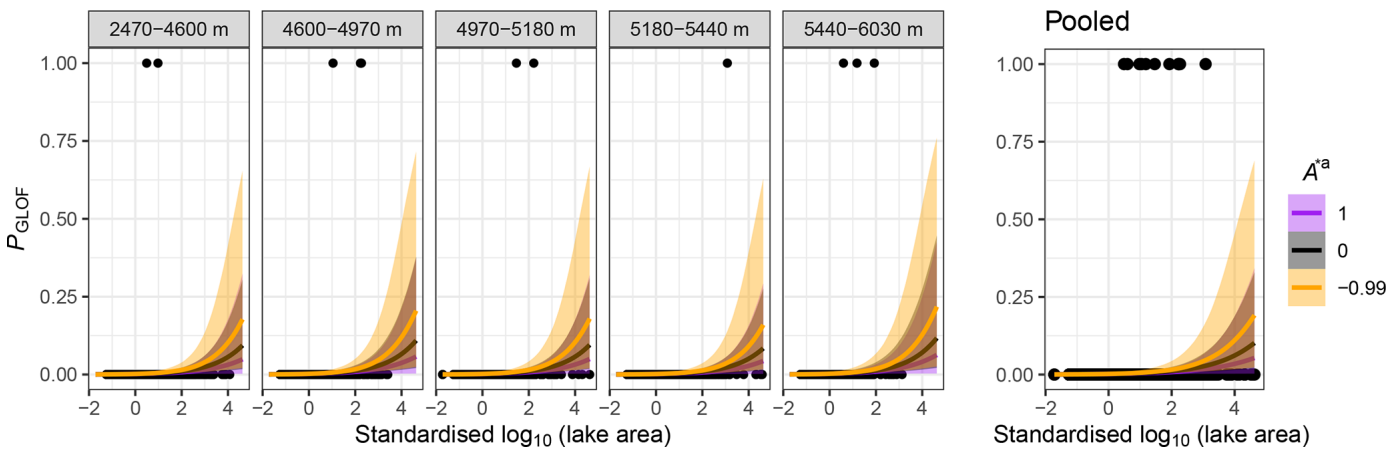

Figure 6. Forecasting model: posterior probabilities $P_{\mathrm{GLOF}}$ as a function of standardised lake area $A$ (in 2005) and standardised lake-area change $A^{* a}$ between 1990 and 2005, grouped by quantiles of elevation (defined in Fig. 1; lowest: 2470-4600 ma.s.1.; low: 4600-4970 ma.s.1.; medium: 4970-5180 ma.s.1.; high: 5180-5440 ma.s.1.; highest: 5440-6030 ma.s.1.). Black dots are lake data with $\left(P_{\mathrm{GLOF}}=1\right)$ or without $\left(P_{\mathrm{GLOF}}=0\right)$ reported GLOF records for the interval 2005 to 2018 . Thick coloured lines are mean fits, and colour shades encompass the associated $95 \%$ HDIs.
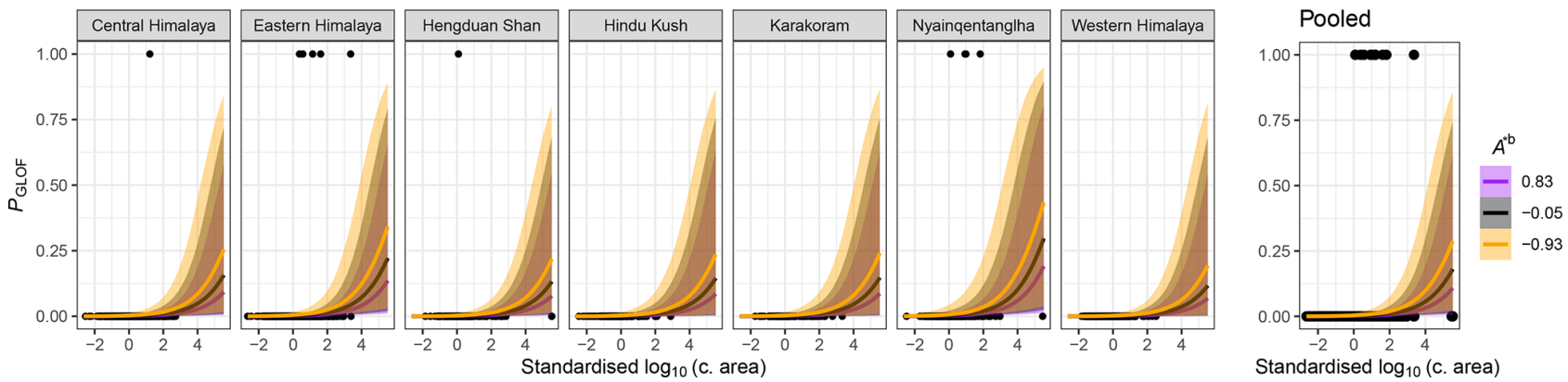

Figure 7. Glacier-mass balance model: posterior probabilities $P_{\mathrm{GLOF}}$ as a function of standardised catchment area $C$ and standardised lakearea change $A^{* b}$ between 2005 and 2018, grouped by regions of average glacier-mass balance (see Fig. 1). Black dots are lake data with $\left(P_{\mathrm{GLOF}}=1\right)$ or without $\left(P_{\mathrm{GLOF}}=0\right)$ reported GLOF records for the interval 2005 to 2018 . Thick coloured lines are mean fits, and colour shades encompass the associated $95 \%$ HDIs.

lates into probabilities using Eq. (3). A positive log-odds ratio means that we obtain a higher posterior probability of attributing a historic GLOF to a given lake compared to a random draw. Negative log-odd ratios indicate lakes for which the posterior probability of a reported GLOF is lower than the prior probability. Based on this metric, all models have higher true positive rates than true negative rates. For a prior probability informed by the historic frequency of GLOFs, the models have at least about $80 \%$ true positives and at least $70 \%$ true negatives on average (Fig. 9, Table 5).

The values of the LOO cross-validation of the predictive capabilities show that the EDW model formally has the least favourable, i.e. higher, values for both LOO metrics (Table 5). This is potentially due to the different true positive counts in the training datasets. However, the range of estimated ELPD values between the remaining three models is small $(\triangle \mathrm{ELPD}=1.9)$.

\section{Discussion}

\subsection{Topographic and climatic predictors of GLOFs}

We used Bayesian multi-level logistic regression to test whether several widely advocated predictors of GLOF susceptibility and glacial lake stability are credible predictors of at least one outburst in the past four decades. All four models that we considered identify lake area and catchment area as predictors with weights that credibly differ from zero with $95 \%$ probability. Our model results quantitatively support qualitative notions of several basin-wide studies in the HKKHN (e.g. Ives et al., 2010; Khadka et al., 2021; Prakash and Nagarajan, 2017) and elsewhere (McKillop and Clague, 2007), which proposed that larger moraine-dammed lakes have a higher potential for releasing GLOFs.

We also found that changes in lake area have partly inconclusive influences in the models. Two exceptions are the negative weight of lake-area changes $\beta_{A^{* b}}$ and $\beta_{A^{* c}}$ in the glacier-mass balance model and in the monsoonality model regardless of the differing intervals that these changes were determined for (Table 4). While this result formally indicates 

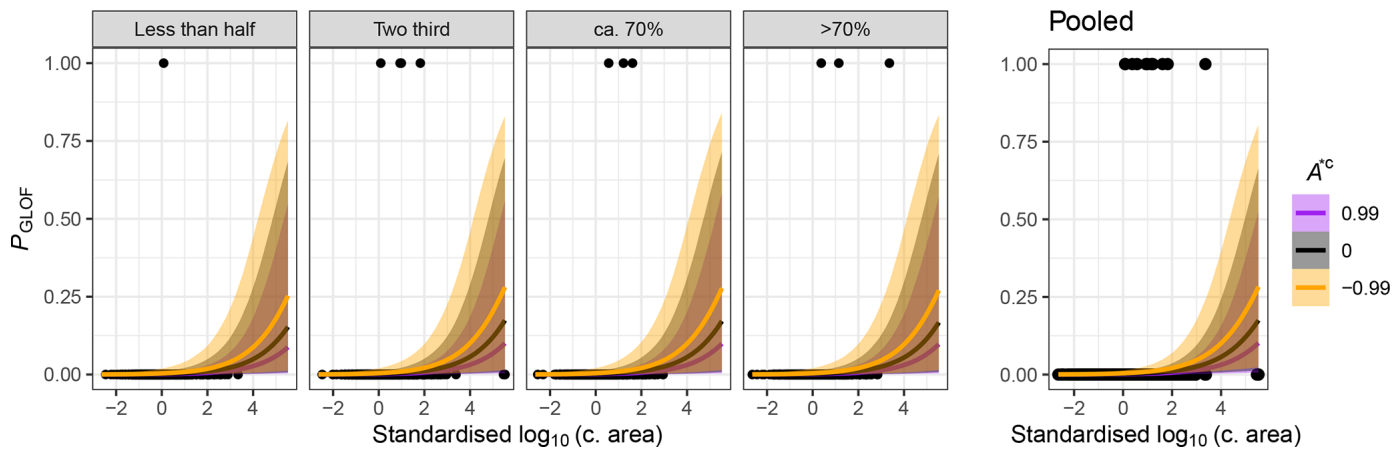

Figure 8. Monsoonality model: posterior probabilities $P_{\mathrm{GLOF}}$ as a function of standardised catchment area $C$ and standardised lake-area change $A^{* c}$ between 1990 and 2018, grouped by quantiles of the annual proportion of precipitation falling during summer (defined in Fig. 1). Black dots are lake data with $\left(P_{\mathrm{GLOF}}=1\right)$ or without $\left(P_{\mathrm{GLOF}}=0\right)$ reported GLOF records for the interval 1990 to 2018 . Thick coloured lines are mean fits, and colour shades encompass the associated $95 \%$ HDIs.

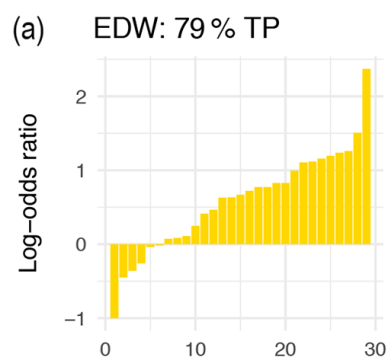

(c)

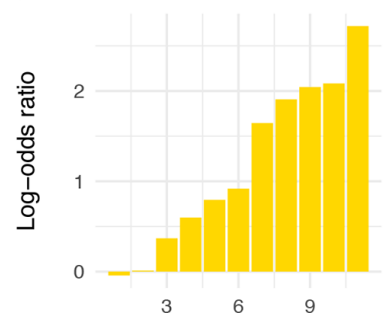

(b) Forecast: $82 \% \mathrm{TP}$

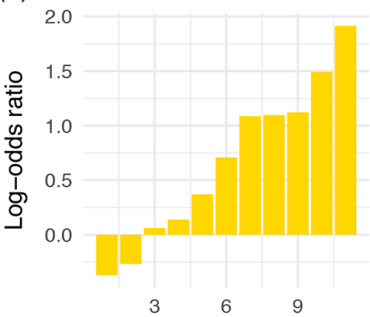

(d)

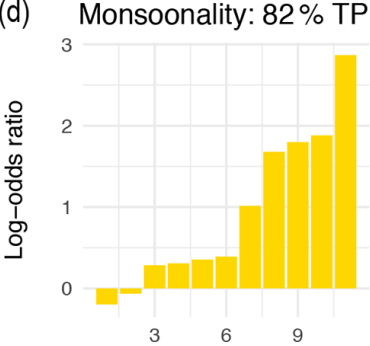

(e) EDW: $74 \%$ TN

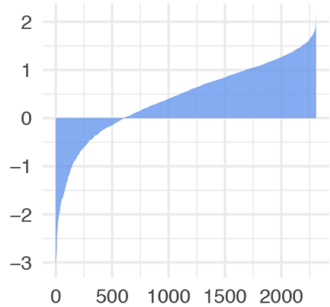

(g)

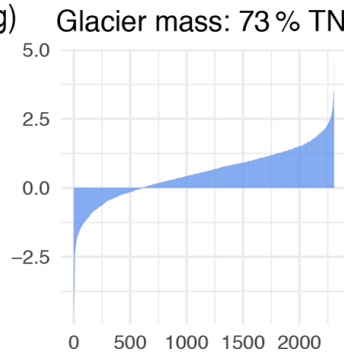

(f) Forecast: $75 \%$ TN

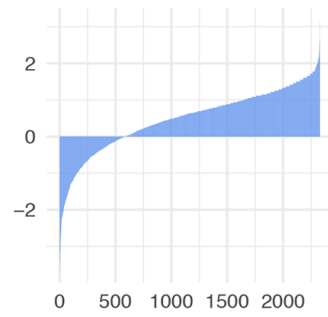

(h) Monsoonality: $72 \%$ TN

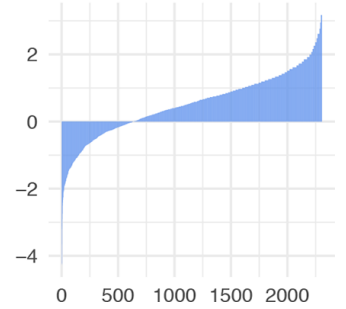

Figure 9. Average posterior log-odds ratios for true positives (TP) (true negatives, TN), i.e. lakes with (without) a GLOF in the period 1981-2018 (a and e) and 2005-2018 (b-d and $\mathbf{f}-\mathbf{h}$ ) on the $x$ axis for the four different models. The log-odds ratios describe here the ratio of the mean posterior over the mean prior probability of classifying a given lake as having had a GLOF. We estimate the mean prior probability from the relative frequency of GLOFs in the datasets. EDW = elevation-dependent warming model.

that shrinking lakes are more likely to be classified as having had a historic GLOF, the period over which these lakearea changes are valid (2005 to 2018) overlaps with the timing of 11 recorded GLOFs (Eq. 9). In other words, the lake shrinkage could be a direct consequence of these GLOFs instead of vice versa. Nonetheless, our results indicate that lake-area changes, either absolute or directional, are somewhat inconclusive in informing us whether a given lake has a recent GLOF history. One advantage of our Bayesian approach is that we can express the role of lake-area changes in GLOF susceptibility by choosing different highest density intervals. For example, if we adopted a narrower, say $80 \%$ HDI for $\Delta A$, we could be $80 \%$ certain that net lakearea growth increased $P_{\mathrm{GLOF}}$ under the elevation-dependent warming model (Eq. 6). However, in the forecasting model, in which we tested whether differing data observation periods have any credible effects, the influence of lake-area change remains negligible even for $<50 \%$ HDIs. We thus conclude that relative lake-area change before outburst is an inconclusive predictor. This result contradicts the assumptions made in many previous studies that argued that rapidly growing lakes are the most prone to sudden outburst (GAPHAZ, 2017; Iribarren Anacona et al., 2014; Ives et al., 2010; Mergili and Schneider, 2011; Prakash and Nagarajan, 2017; Rounce et al., 2016).

The role of elevation in GLOF predictions is also less pronounced than that of lake or catchment area, at least at a group level. The weights of the elevation-dependent warm- 
Table 5. Overview of model validation measures for the predictive capabilities of our models. LOOIC = leave-one-out cross-validation information criterion.

\begin{tabular}{lll|lr}
\hline Model & \multicolumn{1}{c|}{ Prior vs. posterior knowledge } & LOO cross-validation metrics \\
\cline { 2 - 5 } & $\begin{array}{l}\text { \% true positives/ } \\
\% \text { true negatives } \\
\text { correctly identified }\end{array}$ & $\begin{array}{l}\% \text { false positives/ } \\
\text { incolse negatives } \\
\text { inctly identified }\end{array}$ & ELPD & LOOIC \\
\hline Elevation-dependent warming model & $79 \% / 74 \%$ & $21 \% / 26 \%$ & -144.2 & 288.3 \\
Forecasting model & $82 \% / 75 \%$ & $18 \% / 25 \%$ & -66.5 & 132.9 \\
Glacier-mass balance model & $91 \% / 73 \%$ & $9 \% / 27 \%$ & -64.6 & 129.1 \\
Monsoonality model & $82 \% / 72 \%$ & $18 \% / 28 \%$ & -65.6 & 131.2 \\
\hline
\end{tabular}

ing model indicate that lower (higher) lakes are slightly more (less) likely to have had a historic GLOF (Fig. 4) but hardly warrant any better model performance compared to the pooled (or elevation-independent) model. In the forecasting model, however, the contributions of lake elevation to $P_{\mathrm{GLOF}}$ are devoid of any systematic pattern and likely reflect several, potentially combined drivers (Fig. 4). This model was trained on fewer GLOFs, and the imbalance in the data introduces more uncertainties in terms of broad $95 \%$ HDIs. Clearly, the role of elevation may need more future investigation. In terms of elevation bands, it hardly seems to aid GLOF detection with the models used here. Similarly, Emmer et al. (2016) reported that lake elevation was hardly affecting GLOF hazard in the Cordillera Blanca, Peru.

Judging from the regionally averaged glacier-mass balances, our models predict the highest GLOF probabilities in the Nyainqentanglha Mountains and the Eastern Himalaya, which have had the highest historic GLOF counts (Fig. 1). The timing and seasonality of snowfall affect how glaciers respond to rising air temperatures. Observed frequencies and predicted probabilities of historic GLOFs are lowest for several glaciers with positive mass balance in the Karakoram and Western Himalaya (Figs. 1 and 10). Most moraine-dammed lakes in the HKKHN, however, are fed by glaciers with negative mass balances that likely help to elevate GLOF potential through increased meltwater input and glacier-tongue calving rates (Emmer, 2017; Richardson and Reynolds, 2000). This is also supported by the findings of King et al. (2019), which imply that higher rates of mass loss of lake-terminating glaciers since the 1970s might have also led to increased meltwater input into lakes adjacent to their termini. More than $70 \%$ of all lakes that burst out in the past four decades were in contact with their parent glaciers (Veh et al., 2019). However, systematically recorded time series of glacier fronts are even harder to come by when compared to systematic measurements of changes in glacial-lake areas. Given that the regional glacier-mass balance is linked to synoptic precipitation patterns (Kapnick et al., 2014; King et al., 2019; Krishnan et al., 2019), our glacier-mass balance model highlights that the regional ice loss outweighs the role of monsoonality in terms of higher changes to the group-level intercepts for comparable mean $P_{\mathrm{GLOF}}$ and associated uncertainties (Figs. 4, 7 and 8).

Our results offer insights into the links between historic GLOFs and the synoptic precipitation patterns. Richardson and Reynolds (2000) presumed that seasonal floods and GLOFs are both caused by high monsoonal precipitation and summer ablation. In contrast, our results indicate that the fraction of summer precipitation changes the predictive probabilities of historic GLOFs only marginally, at least at the group level, so that deviations from a pooled model for the HKKHN are minute when compared to the spread of posterior group-level intercepts in the other models (Fig. 4). In essence, our results underline the need for exploring more the interactions of both precipitation and temperature as potential GLOF triggers. It may well be that seasonal timing of heavy precipitation events and type (rain or snow) at a given lake may be more meaningful to GLOF susceptibility than annual totals or averages. Whether our finding that glacier-mass balances driven by superimposed synoptic regimes credibly influence regional GLOF susceptibility in the HKKHN is applicable to other regions, for example the Cordillera Blanca in the South American Andes (Emmer et al., 2016; Emmer and Vilímek, 2014; Iturrizaga, 2011), also needs further investigation.

\subsection{Model assessment}

We consider our quantitative and data-driven approach as complementary to existing qualitative and basin-wide GLOF hazard appraisals. Our models cannot replace field observations that deliver local details on GLOF-disposing factors such as moraine or adjacent rock-slope stability, presence of ice cores, glacier calving rates, or surges. Our selection of predictors is a compromise between widely used predictors of GLOF susceptibility and hazard and their availability as data covering the entire HKKHN. To this end, we used lake (or catchment) area and lake-area changes as predictors, as well as elevation, regional glacier-mass balance, and monsoonality as group levels of past GLOF activity of several thousand moraine-dammed lakes in the HKKHN. Among the many possible combinations of predictors and group levels we focused on those few combinations with minimal corre- 
(a)

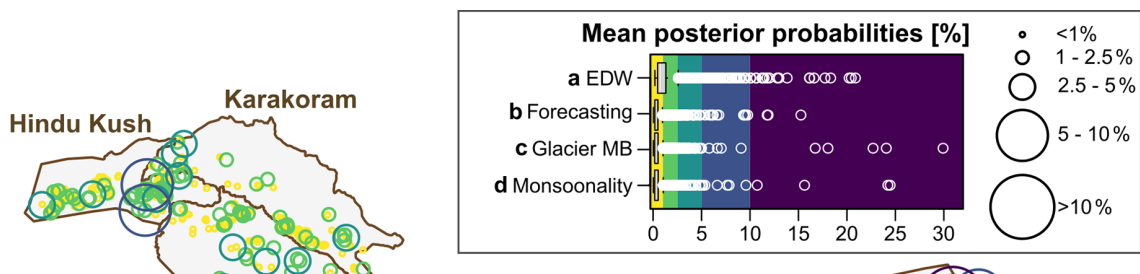

(b)

(c)

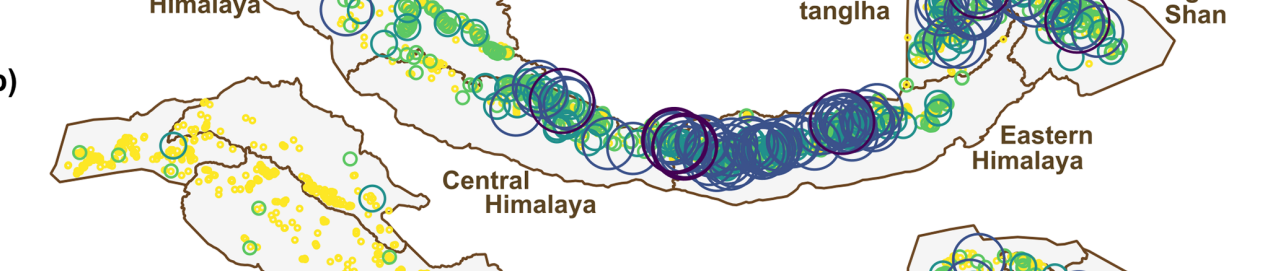

(d)

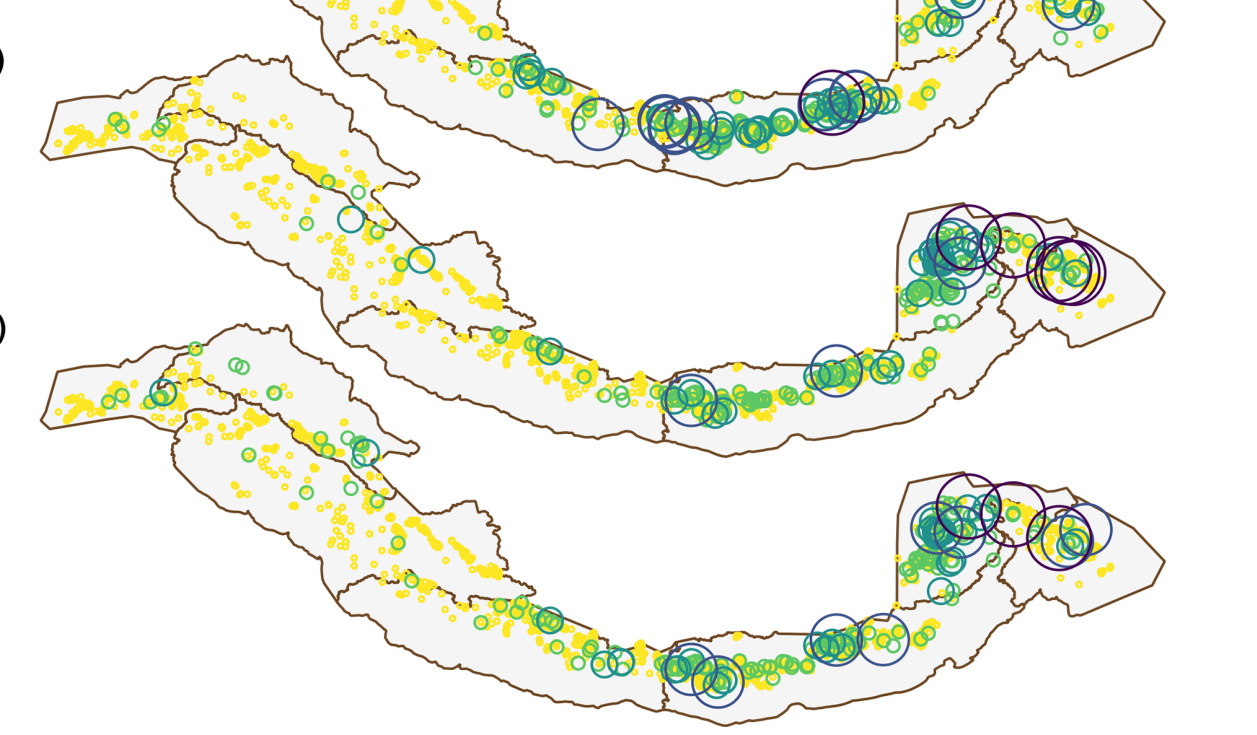

Figure 10. Mean posterior probabilities of HKKHN glacial lakes for having had a GLOF history $\left(P_{\mathrm{GLOF}}\right)$ in the past four decades as estimated in the (a) elevation-dependent warming model, (b) forecasting model, (c) glacier-mass balance model, and (d) monsoonality model. Size and colours of bubbles are scaled by posterior probabilities.

lation among the input variables. We minimised the potential for misclassification by using a purely remote-sensingbased inventory of GLOFs, which reduces reporting bias for GLOFs too small to be noticed or happening in unpopulated areas: more destructive GLOFs are recorded more often than smaller GLOFs in remote areas (Veh et al., 2018, 2019). We are thus confident that we trained our models on lakes with a confirmed GLOF history at the expense of discarding known outbursts predating the onset of Landsat satellite coverage in 1981. We acknowledge that climate products such as precipitation can have large biases because of orographic effects or climate circulation patterns and interpolation using topography (Karger et al., 2017; Mukul et al., 2017). Cross-validation of CHELSA precipitation estimates with station data has a global mean coefficient of determination $R^{2}$ of 0.77 , with regional variations between 0.53 and 0.90 (Karger et al., 2017). By accounting for orographic wind effects, CHELSA products outperform previous global datasets such as the WorldClim (Hijmans et al., 2005), especially in the rugged HKKHN topography. We stress that we therefore used all climatic data as aggregated group-level variables to avoid spurious model results. At the level of individual lakes, we thus resorted only to size, elevation, and upstream catchment area as more robust predictors.

Due to strong imbalance in our training data, we opted for a prior vs. posterior log-odd comparison instead of commonly applied receiver operating characteristics (ROCs) in estimating the predictive capabilities of our models (Saito and Rehmsmeier, 2015). In our models, only a few posterior estimates of $P_{\mathrm{GLOF}}$ are $>0.5$, and they thus offer very conservative estimates of a GLOF history (Fig. 10). All models have wide $95 \%$ HDIs that attest to a high level of uncertainty. This observation may be sobering but nevertheless documents objectively the minimum amount of accuracy that 
these simple models afford for objectively detecting historic outbursts.

The low fraction of lakes with a GLOF history $(\sim 1 \%)$ curtails a traditional logistic regression model and favours instead a Bayesian multi-level approach that can handle imbalanced training data and collinear predictors (Gelman and Hill, 2007; Hille Ris Lambers et al., 2006; Shor et al., 2007). We prefer the straight-forward interpretation of posterior regression weights to random forest classifiers, neural networks, or support vector machines (Caniani et al., 2008; Falah et al., 2019; Kalantar et al., 2018; Taalab et al., 2018). While these methods may perform better, they disclose little about the relationship between model inputs and outputs (Blöthe et al., 2019; Dinov, 2018); much of their higher accuracy is also linked to the overwhelming number of true negatives. Yet so far, multi-criteria decision analysis or decisionmaking trees have been the method of choice in GLOF hazard assessments, both in High Mountain Asia (Bolch et al., 2011; Prakash and Nagarajan, 2017; Rounce et al., 2016; Wang et al., 2012) and elsewhere (Emmer et al., 2016; Emmer and Vilímek, 2014; Huggel et al., 2002; Kougkoulos et al., 2018). While these methods strongly rely on expert judgement (Allen et al., 2019), a Bayesian logistic regression encodes any prior knowledge or constraints explicitly and reproducibly as probability distributions. Still, inconsiderate or inappropriate prior choices can introduce bias (Van Dongen, 2006; Kruschke and Liddell, 2018). Therefore, we carefully considered our choice of weakly informative priors for predictors with limited prior knowledge, following the guidelines concerning regression models by Gelman (2006) and Gelman et al. (2008). We also cross-checked our results when applying varying prior choices and found negligible differences in the resulting posterior distributions.

To summarise, our simple classification models hardly support the notion that elevation or changes in lake area are straightforward predictors of a GLOF history, at least for the moraine-dammed lakes that we studied in the HKKHN. Lake size and regional differences in glacier-mass balance are items that future studies of GLOF susceptibility may wish to consider further. The performance of these models is moderate to good if compared to a random classification, yet it is associated with high uncertainties in terms of wide highest density intervals. We underline that these uncertainties have rarely been addressed, let alone quantified, in previous work. One way forward may be to create ensembles of such models to improve their predictive capability instead of relying on any single model.

\section{Conclusions}

We quantitatively investigated the susceptibility of morainedammed lakes to GLOFs in major mountain regions of High Asia. We used a systematically compiled and comprehensive inventory of moraine-dammed lakes with docu- mented GLOFs in the past four decades to test how elevation, lake area and its rate of change, glacier-mass balance, and monsoonality perform as predictors and group levels in a Bayesian multi-level logistic regression. Our results show that larger lakes in larger catchments have been more prone to sudden outburst floods, as have those lakes in regions with pronounced negative glacier-mass balance. While elevationdependent warming (EDW) may control a number of processes conducive to GLOFs, grouping our classification by elevation bands adds little to a pooled model for the entire HKKHN. Historic changes in lake area, both in absolute and relative values, have an ambiguous role in these models. We observed that shrinking lakes favour the classification as GLOF-prone, although this may arise from overlapping measurement intervals such that the reduction in lake size arises from outburst rather than vice versa. In any case, the widely adapted notion that (rapid) lake growth may be a predictor of impending outburst remains poorly supported by our model results. Our Bayesian approach allows explicit probabilistic prognoses of the role of these widely cited controls on GLOF susceptibility but also attests to previously hardly quantified uncertainties, especially for the larger lakes in our study area. While individual models offer some improvement with respect to a random classification based on average GLOF frequency, we recommend considering ensemble models for obtaining more accurate and flexible predictions of outbursts from moraine-dammed lakes.

Code and data availability. This study is based on freely available data. Shuttle Radar Topography Mission (SRTM) data are available from the US Geological Survey (https://earthexplorer.usgs.gov/, last access: 6 August 2021). We derived climatic variables from the CHELSA Bioclim dataset (https://chelsa-climate.org/bioclim/, last access: 6 August 2021) described by Karger et al. (2017) and regional glacier-mass balances from Brun et al. (2017). We extracted glacial lake information from inventories published by Maharjan et al. (2018), Veh et al. (2019), and Wang et al. (2020). We processed our data with free R statistical software (https://cran.r-project.org/, last access: 6 August 2021), including the brms package by Bürkner (2017) (https://CRAN.R-project.org/package=brms, last access: 6 August 2021). The model code to this article by Fischer et al. (2020) is published in a GitHub repository and is available online at https://doi.org/10.5281/zenodo.4161577 (Fischer et al., 2020).

Author contributions. This study was conceptualised by all authors. While formal analysis and methodology were conducted by MF and OK, data curation was mainly carried out by GV. Visualisations of data and results, including maps, were prepared by GV, $\mathrm{OK}$, and MF. MF prepared the original manuscript; OK, GV, and AW reviewed and edited the writing.

Competing interests. The authors declare that they have no conflict of interest. 
Disclaimer. Publisher's note: Copernicus Publications remains neutral with regard to jurisdictional claims in published maps and institutional affiliations.

Acknowledgements. This research was funded by the Deutsche Forschungsgemeinschaft (DFG) via the graduate research training group NatRiskChange at the University of Potsdam (https://www. natriskchange.de, last access: 6 August 2021). We thank Adam Emmer and Holger Frey for their helpful reviews of an earlier version of this article.

Financial support. This research has been supported by the Deutsche Forschungsgemeinschaft (grant nos. GRK 2043/1 and GRK 2043/2).

Review statement. This paper was edited by Tobias Bolch and reviewed by Adam Emmer and Holger Frey.

\section{References}

Aggarwal, A., Jain, S. K., Lohani, A. K., and Jain, N.: Glacial lake outburst flood risk assessment using combined approaches of remote sensing, GIS and dam break modelling, Geomat. Nat. Haz. Risk, 7, 18-36, https://doi.org/10.1080/19475705.2013.862573, 2016.

Allen, S. K., Rastner, P., Arora, M., Huggel, C., and Stoffel, M.: Lake outburst and debris flow disaster at Kedarnath, June 2013: hydrometeorological triggering and topographic predisposition, Landslides, 13, 1479-1491, https://doi.org/10.1007/s10346-0150584-3, 2016.

Allen, S. K., Zhang, G., Wang, W., Yao, T., and Bolch, T.: Potentially dangerous glacial lakes across the Tibetan Plateau revealed using a large-scale automated assessment approach, Sci. Bull., 64, 435-445, https://doi.org/10.1016/j.scib.2019.03.011, 2019.

Austin, P. C., Tu, J. V., and Alter, D. A.: Comparing hierarchical modeling with traditional logistic regression analysis among patients hospitalized with acute myocardial infarction: Should we be analyzing cardiovascular outcomes data differently?, Am. Heart J., 145, 27-35, https://doi.org/10.1067/mhj.2003.23, 2003.

Bajracharya, S. R. and Shrestha, B.: The Status of Glaciers in the Hindu Kush-Himalayan Region, International Centre for Integrated Mountain Development (ICIMOD), Kathmandu, 2011.

Blöthe, J. H., Rosenwinkel, S., Höser, T., and Korup, O.: Rockglacier dams in High Asia, Earth Surf. Proc. Land., 44, 808-824, https://doi.org/10.1002/esp.4532, 2019.

Bolch, T., Peters, J., Yegorov, A., Pradhan, B., Buchroithner, M., and Blagoveshchensky, V.: Identification of potentially dangerous glacial lakes in the northern Tien Shan, Nat. Hazards, 59, 1691-1714, https://doi.org/10.1007/s11069-011-9860-2, 2011.

Bolch, T., Shea, J. M., Liu, S., Azam, F. M., Gao, Y., Gruber, S., Immerzeel, W. W., Kulkarni, A., Li, H., Tahir, A. A., Zhang, G., and Zhang, Y.: Status and Change of the Cryosphere in the Extended Hindu Kush Himalaya Region, in The Hindu Kush Himalaya Assessment: Mountains, Climate Change, Sustainability and People, edited by P. Wester, A. Mishra, A. Mukherji, and
A. B. Shrestha, pp. 209-255, Springer International Publishing, Cham., 2019.

Bookhagen, B. and Burbank, D. W.: Toward a complete Himalayan hydrological budget: Spatiotemporal distribution of snowmelt and rainfall and their impact on river discharge, J. Geophys. Res. Earth Surf., 115, 1-25, https://doi.org/10.1029/2009JF001426, 2010.

Brun, F., Berthier, E., Wagnon, P., Kääb, A., and Treichler, D.: A spatially resolved estimate of High Mountain Asia glacier mass balances from 2000 to 2016, Nat. Geosci., 10, 668-673, https://doi.org/10.1038/ngeo2999, 2017.

Bürkner, P.-C.: brms: An $\mathrm{R}$ package for Bayesian multilevel models using Stan, J. Stat. Softw., 80, 1-28, https://doi.org/10.18637/jss.v080.i01, 2017.

Caniani, D., Pascale, S., Sdao, F., and Sole, A.: Neural networks and landslide susceptibility: A case study of the urban area of Potenza, Nat. Hazards, 45, 55-72, https://doi.org/10.1007/s11069-007-9169-3, 2008.

Carrivick, J. L. and Tweed, F. S.: A global assessment of the societal impacts of glacier outburst floods, Global Planet. Change, 144 1-16, https://doi.org/10.1016/j.gloplacha.2016.07.001, 2016.

Cenderelli, D. A. and Wohl, E. E.: Flow hydraulics and geomorphic effects of glacial-lake outburst floods in the Mount Everest region, Nepal, Earth Surf. Proc. Land., 28, 385-407, https://doi.org/10.1002/esp.448, 2003.

Chen, F., Zhang, M., Guo, H., Allen, S., Kargel, J. S., Haritashya, U. K., and Watson, C. S.: Annual $30 \mathrm{~m}$ dataset for glacial lakes in High Mountain Asia from 2008 to 2017, Earth Syst. Sci. Data, 13, 741-766, https://doi.org/10.5194/essd-13-741-2021, 2021.

Cook, K. L., Andermann, C., Gimbert, F., Adhikari, B. R., and Hovius, N.: Glacial lake outburst floods as drivers of fluvial erosion in the Himalaya, Science, 362, 53-57, https://doi.org/10.1126/science.aat4981, 2018.

Costa, J. E. and Schuster, R. L.: The Formation and Failure of Natural Dams, U.S. Geological Survey (USGS), Vancouver, 1987.

Dehecq, A., Gourmelen, N., Gardner, A. S., Brun, F., Goldberg, D., Nienow, P. W., Berthier, E., Vincent, C., Wagnon, P., and Trouvé, E.: Twenty-first century glacier slowdown driven by mass loss in High Mountain Asia, Nat. Geosci., 12, 22-27, https://doi.org/10.1038/s41561-018-0271-9, 2019.

Dinov, I. D.: Data science and predictive analytics: Biomedical and health applications using R, Springer, Cham, 2018.

Dubey, S. and Goyal, M. K.: Glacial Lake Outburst Flood Hazard, Downstream Impact, and Risk Over the Indian Himalayas, Water Resour. Res., 56, 1-21, https://doi.org/10.1029/2019WR026533, 2020.

Emmer, A.: Glacier Retreat and Glacial Lake Outburst Floods (GLOFs), Oxford Res. Encycl. Nat. Hazard Sci., 1-37, https://doi.org/10.1093/acrefore/9780199389407.013.275, 2017.

Emmer, A. and Vilímek, V.: Review Article: Lake and breach hazard assessment for moraine-dammed lakes: an example from the Cordillera Blanca (Peru), Nat. Hazards Earth Syst. Sci., 13, 1551-1565, https://doi.org/10.5194/nhess-13-1551-2013, 2013.

Emmer, A. and Vilímek, V.: New method for assessing the susceptibility of glacial lakes to outburst floods in the Cordillera Blanca, Peru, Hydrol. Earth Syst. Sci., 18, 3461-3479, https://doi.org/10.5194/hess-18-3461-2014, 2014.

Emmer, A., Klimeš, J., Mergili, M., Vilímek, V., and Cochachin, A.: 882 lakes of the Cordillera Blanca: An 
inventory, classification, evolution and assessment of susceptibility to outburst floods, Catena, 147, 269-279, https://doi.org/10.1016/j.catena.2016.07.032, 2016.

Etzelmüller, B. and Frauenfelder, R.: Factors controlling the distribution of mountain permafrost in the northern hemisphere and their influence on sediment transfer, Arct. Antarct. Alp. Res., 41, 48-58, https://doi.org/10.1657/1523-0430-41.1.48, 2009.

Evans, S. G. and Clague, J. J.: Recent climatic change and catastrophic geomorphic processes in mountain environments, Geomorphology, 10, 107-128, https://doi.org/10.1016/0169555X(94)90011-6, 1994.

Falah, F., Rahmati, O., Rostami, M., Ahmadisharaf, E., Daliakopoulos, I. N., and Pourghasemi, H. R.: Artificial Neural Networks for Flood Susceptibility Mapping in Data-Scarce Urban Areas, in: Spatial Modeling in GIS and R for Earth and Environmental Sciences, edited by: Pourghasemi, H. R. and Gokceoglu, C., Elsevier, Amsterdam, pp. 323-336, 2019.

Fischer, M., Korup, O., Veh, G., and Walz, A.: GLOFsusceptibility: First release of the GLOF susceptibility model (Version v.1.0), Zenodo, https://doi.org/10.5281/zenodo.4161577, 2020.

Fujita, K., Suzuki, R., Nuimura, T., and Sakai, A.: Performance of ASTER and SRTM DEMs, and their potential for assessing glacial lakes in the Lunana region, Bhutan Himalaya, J. Glaciol., 54, 220-228, https://doi.org/10.3189/002214308784886162, 2008.

GAPHAZ: Assessment of Glacier and Permafrost Hazards in Mountain Regions: Technical Guidance Document, Standing Group on Glacier and Permafrost Hazards in Mountains (GAPHAZ) of the International Association of Cryospheric Sciences (IACS) and the International Permafrost Association (IPA), Zürich, Lima, 2017.

Gelman, A.: Prior distributions for variance parameters in hierarchical models, Bayesian Anal., 1, 515-533, https://doi.org/10.1002/cjs.5550340302, 2006.

Gelman, A. and Hill, J.: Data Analysis using Regression and Multilevel/Hierarchical Models, Cambridge University Press, New York, 2007.

Gelman, A., Jakulin, A., Pittau, M. G., and Su, Y. S.: A weakly informative default prior distribution for logistic and other regression models, Ann. Appl. Stat., 2, 1360-1383, https://doi.org/10.1214/08-AOAS191, 2008.

Haeberli, W., Schaub, Y., and Huggel, C.: Increasing risks related to landslides from degrading permafrost into new lakes in de-glaciating mountain ranges, Geomorphology, 293, 405-417, https://doi.org/10.1016/j.geomorph.2016.02.009, 2017.

Hijmans, R. J., Cameron, S. E., Parra, J. L., Jones, P. G., and Jarvis, A.: Very high resolution interpolated climate surfaces for global land areas, Int. J. Climatol., 25, 1965-1978, https://doi.org/10.1002/joc.1276, 2005.

Hille Ris Lambers, J., Aukema, B., Diez, J., Evans, M., and Latimer, A.: Effects of global change on inflorescence production: a Bayesian hierarchical analysis, in Hierarchical Modelling for the Environmental Sciences - Statistical Methods and Applications, edited by: Clark, J. S. and Gelfand, A. E., Oxford University Press North Carolina, Cary., 59-76, 2006.

Hock, R., Rasul, G., Adler, C., Cáceres, B., Gruber, S., Hirabayashi, Y., Jackson, M., Kääb, A., Kang, S., Kutuzov, S., Milner, A., Molau, U., Morin, S., Orlove, B., and Steltzer, H. I.: High Mountain Areas, in: IPCC Special Report on the Ocean and Cryosphere in a Changing Climate, edited by: Pörtner, H.-O., Roberts, D. C., Masson-Delmotte, V., Zhai, P., Tignor, M., Poloczanska, E., Mintenbeck, K., Alegría, A., Nicolai, M., Okem, A., Petzold, J., Rama, B., Weyer, N. M., Intergovernmental Panel on Climate Change (IPCC), Genf, 131-202, 2019.

Huggel, C., Kääb, A., Haeberli, W., Teysseire, P., and Paul, F.: Remote sensing based assessment of hazards from glacier lake outbursts: a case study in the Swiss Alps, Can. Geotech. J., 39, 316330, https://doi.org/10.1139/t01-099, 2002.

Huggel, C., Haeberli, W., Kääb, A., Bieri, D., and Richardson, S.: An assessment procedure for glacial hazards in the Swiss Alps, Can. Geotech. J., 41, 1068-1083, https://doi.org/10.1139/T04053, 2004.

Iribarren Anacona, P., Norton, K. P., and Mackintosh, A.: Morainedammed lake failures in Patagonia and assessment of outburst susceptibility in the Baker Basin, Nat. Hazards Earth Syst. Sci., 14, 3243-3259, https://doi.org/10.5194/nhess-143243-2014, 2014.

Iturrizaga, L.: Glacier Lake Outburst Floods, in: Encyclopedia of Snow, Ice and Glaciers, edited by: Singh, V. P., Singh, P., and Haritashya, U. K., Springer Netherlands, Dodrecht, pp. 381-399, 2011.

Ives, J. D., Shrestha, R. B., and Mool, P. K.: Formation of Glacial Lakes in the Hindu Kush-Himalayas and GLOF Risk Assessment, International Centre for Integrated Mountain Development (ICIMOD), Kathmandu, 2010.

Kalantar, B., Pradhan, B., Naghibi, S. A., Motevalli, A., and Mansor, S.: Assessment of the effects of training data selection on the landslide susceptibility mapping: a comparison between support vector machine (SVM), logistic regression (LR) and artificial neural networks (ANN), Geomat. Nat. Haz. Risk, 9, 49-69, https://doi.org/10.1080/19475705.2017.1407368, 2018.

Kapnick, S. B., Delworth, T. L., Ashfaq, M., Malyshev, S., and Milly, P. C. D.: Snowfall less sensitive to warming in Karakoram than in Himalayas due to a unique seasonal cycle, Nat. Geosci., 7, 834-840, https://doi.org/10.1038/ngeo2269, 2014.

Karger, D. N., Conrad, O., Böhner, J., Kawohl, T., Kreft, H., SoriaAuza, R. W., Zimmermann, N. E., Linder, H. P., and Kessler, M.: Climatologies at high resolution for the earth's land surface areas, Sci. Data, 4, 1-20, https://doi.org/10.1038/sdata.2017.122, 2017.

Khadka, N., Chen, X., Nie, Y., Thakuri, S., and Zheng, G.: Evaluation of Glacial Lake Outburst Flood Susceptibility Using MultiCriteria Assessment Framework in Mahalangur Himalaya, Front. Earth Sci., 8, 1-16, https://doi.org/10.3389/feart.2020.601288, 2021.

King, O., Bhattacharya, A., Bhambri, R., and Bolch, T.: Glacial lakes exacerbate Himalayan glacier mass loss, Sci. Rep.-UK, 9, 1-9, https://doi.org/10.1038/s41598-019-53733-x, 2019.

Koike, T. and Takenaka, S.: Scenario Analysis on Risks of Glacial Lake Outburst Floods on the Mangde Chhu River, Bhutan, Glob. Environ. Res., 16, 41-49, 2012.

Kougkoulos, I., Cook, S. J., Jomelli, V., Clarke, L., Symeonakis, E., Dortch, J. M., Edwards, L. A., and Merad, M. Use of multi-criteria decision analysis to identify potentially dangerous glacial lakes, Sci. Total Environ., 621, 1453-1466, https://doi.org/10.1016/j.scitotenv.2017.10.083, 2018.

Kraaijenbrink, P. D. A., Bierkens, M. F. P., Lutz, A. F., and Immerzeel, W. W.: Impact of a global temperature rise of 
1.5 degrees Celsius on Asia's glaciers, Nature, 549, 257-260, https://doi.org/10.1038/nature23878, 2017.

Krishnan, R., Shrestha, A. B., Ren, G., Rajbhandari, R., Saeed, S., Sanjay, J., Syed, M. A., Vellore, R., Xu, Y., You, Q., and Ren, Y.: Unravelling Climate Change in the Hindu Kush Himalaya: Rapid Warming in the Mountains and Increasing Extremes, in: The Hindu Kush Himalaya Assessment: Mountains, Climate Change, Sustainability and People, edited by: Wester, P., Mishra, A., Mukherji, A., and Shrestha, A. B., Springer International Publishing, Cham, pp. 57-97, 2019.

Kruschke, J. K. and Liddell, T. M.: Bayesian data analysis for newcomers, Psychon. B. Rev., 25, 155-177, https://doi.org/10.3758/s13423-017-1272-1, 2018.

Liu, J. J., Cheng, Z. L., and Su, P. C.: The relationship between air temperature fluctuation and Glacial Lake Outburst Floods in Tibet, China, Quatern. Int., 321, 78-87, https://doi.org/10.1016/j.quaint.2013.11.023, 2014.

Maharjan, S. B., Mool, P. K., Lizong, W., Xiao, G., Shrestha, F., Shrestha, R. B., Khanal, N. R., Bajracharya, S. R., Joshi, S., Shai, S., and Baral, P.: The Status of Glacial Lakes in the Hindu Kush Himalaya, International Centre for Integrated Mountain Development (ICIMOD), Kathmandu, 2018.

Maurer, J. M., Schaefer, J. M., Rupper, S., and Corley, A.: Acceleration of ice loss across the Himalayas over the past 40 years, Science Advances, 5, eaav7266, https://doi.org/10.1126/sciadv.aav7266, 2019.

McKillop, R. J. and Clague, J. J.: Statistical, remote sensingbased approach for estimating the probability of catastrophic drainage from moraine-dammed lakes in southwestern British Columbia, Global Planet. Change, 56, 153-171, https://doi.org/10.1016/j.gloplacha.2006.07.004, 2007.

Mergili, M. and Schneider, J. F.: Regional-scale analysis of lake outburst hazards in the southwestern Pamir, Tajikistan, based on remote sensing and GIS, Nat. Hazards Earth Syst. Sci., 11, 14471462, https://doi.org/10.5194/nhess-11-1447-2011, 2011.

Molden, D. J., Vaidya, R. A., Shrestha, A. B., Rasul, G., and Shrestha, M. S.: Water infrastructure for the Hindu Kush Himalayas, Int. J. Water Resour. D., 30, 60-77, https://doi.org/10.1080/07900627.2013.859044, 2014.

Mool, P. K., Maskey, P. R., Koirala, A., Joshi, S. P., Wu, L., Shrestha, A. B., Eriksson, M., Gurung, B., Pokharel, B., Khanal, N. R., Panthi, S., Adhikari, T., Kayastha, R. B., Ghimire, P., Thapa, R., Shrestha, B., Shrestha, S., and Shrestha, R. B.: Glacial Lakes and Glacial Lake Outburst Floods in Nepal, International Centre for Integrated Mountain Development (ICIMOD), Kathmandu, 2011.

Mukul, M., Srivastava, V., Jade, S., and Mukul, M.: Uncertainties in the Shuttle Radar Topography Mission (SRTM) Heights: Insights from the Indian Himalaya and Peninsula, Sci. Rep.-UK, 7, 1-10, https://doi.org/10.1038/srep41672, 2017.

Nalborczyk, L., Batailler, C., Loevenbruck, H., Vilain, A., and Bürkner, P. C.: An introduction to bayesian multilevel models using brms: A case study of gender effects on vowel variability in standard Indonesian, J. Speech Lang. Hear. R., 62, 1225-1242, https://doi.org/10.1044/2018_JSLHR-S-18-0006, 2019.

Nie, Y., Sheng, Y., Liu, Q., Liu, L., Liu, S., Zhang, Y., and Song, C.: A regional-scale assessment of Himalayan glacial lake changes using satellite observations from 1990 to 2015, Remote Sens.
Environ., 189, 1-13, https://doi.org/10.1016/j.rse.2016.11.008, 2017.

Nie, Y., Liu, Q., Wang, J., Zhang, Y., Sheng, Y., and Liu, S.: An inventory of historical glacial lake outburst floods in the Himalayas based on remote sensing observations and geomorphological analysis, Geomorphology, 308, 91-106, https://doi.org/10.1016/j.geomorph.2018.02.002, 2018.

Palazzi, E., von Hardenberg, J., and Provenzale, A.: Precipitation in the Hindu-Kush Karakoram Himalaya: Observations and future scenarios, J. Geophys. Res.-Atmos., 118, 85-100, https://doi.org/10.1029/2012JD018697, 2013.

Palazzi, E., Filippi, L., and von Hardenberg, J.: Insights into elevation-dependent warming in the Tibetan Plateau-Himalayas from CMIP5 model simulations, Clim. Dynam., 48, 3991-4008, https://doi.org/10.1007/s00382-016-3316-z, 2017.

Pepin, N., Bradley, R. S., Diaz, H. F., Baraer, M., Caceres, E. B., Forsythe, N., Fowler, H., Greenwood, G., Hashmi, M. Z., Liu, X. D., Miller, J. R., Ning, L., Ohmura, A., Palazzi, E., Rangwala, I., Schöner, W., Severskiy, I., Shahgedanova, M., Wang, M. B., Williamson, S. N., and Yang, D. Q.: Elevation-dependent warming in mountain regions of the world, Nat. Clim. Change, 5, 424-430, https://doi.org/10.1038/nclimate2563, 2015.

Prakash, C. and Nagarajan, R.: Outburst susceptibility assessment of moraine-dammed lakes in Western Himalaya using an analytic hierarchy process, Earth Surf. Proc. Land., 42, 2306-2321, https://doi.org/10.1002/esp.4185, 2017.

Rangwala, I. and Miller, J. R.: Climate change in mountains: A review of elevation-dependent warming and its possible causes, Climatic Change, 114, 527-547, https://doi.org/10.1007/s10584012-0419-3, 2012.

RGI Consortium: Randolph Glacier Inventory - A Dataset of Global Glacier Outlines: Version 6.0: Technical Report, Global Land Ice Measurements from Space (GLIM), Boulder., 2017.

Richardson, S. D. and Reynolds, J. M.: An overview of glacial hazards in the Himalayas, Quatern. Int., 65/66, 31-47, https://doi.org/10.1016/S1040-6182(99)00035-X, 2000.

Rolland, C.: Spatial and seasonal variations of air temperature lapse rates in alpine regions, J. Climate, 16, 1032-1046, https://doi.org/10.1175/15200442(2003)016<1032:SASVOA>2.0.CO;2, 2003.

Rounce, D. R., McKinney, D. C., Lala, J. M., Byers, A. C., and Watson, C. S.: A new remote hazard and risk assessment framework for glacial lakes in the Nepal Himalaya, Hydrol. Earth Syst. Sci., 20, 3455-3475, https://doi.org/10.5194/hess-20-3455-2016, 2016.

Saito, T. and Rehmsmeier, M.: The Precision-Recall Plot Is More Informative than the ROC Plot When Evaluating Binary Classifiers on Imbalanced Datasets, PLoS One, 10, 1-25, https://doi.org/10.1371/journal.pone.0118432, 2015.

Shor, B., Bafumi, J., Keele, L., and Park, D.: A Bayesian multilevel modeling approach to time-series cross-sectional data, Polit. Anal., 15, 165-181, https://doi.org/10.1093/pan/mpm006, 2007.

Somos-Valenzuela, M. A., McKinney, D. C., Byers, A. C., Voss, K., Moss, J., and McKinney, J. C.: Ground Penetrating Radar Survey for Risk Reduction at Imja Lake, Nepal, Center for Research in Water Resources (CRWR), Austin, available at: http://hdl.handle. net/2152/19751 (last access: 30 October 2020), 2012. 
Somos-Valenzuela, M. A., McKinney, D. C., Byers, A. C., Rounce, D. R., Portocarrero, C., and Lamsal, D.: Assessing downstream flood impacts due to a potential GLOF from Imja Tsho in Nepal, Hydrol. Earth Syst. Sci., 19, 1401-1412, https://doi.org/10.5194/hess-19-1401-2015, 2015.

Stegmueller, D.: How many countries for multilevel modeling? A comparison of frequentist and bayesian approaches, Am. J. Polit. Sci., 57, 748-761, https://doi.org/10.1111/ajps.12001, 2013.

Taalab, K., Cheng, T., and Zhang, Y.: Mapping landslide susceptibility and types using Random Forest, Big Earth Data, 2, 159178, https://doi.org/10.1080/20964471.2018.1472392, 2018.

Terzago, S., von Hardenberg, J., Palazzi, E., and Provenzale, A.: Snowpack Changes in the Hindu Kush-Karakoram-Himalaya from CMIP5 Global Climate Models, J. Hydrometeorol., 15, 2293-2313, https://doi.org/10.1175/JHM-D-13-0196.1, 2014.

Tudoroiu, M., Eccel, E., Gioli, B., Gianelle, D., Schume, H., Genesio, L., and Miglietta, F.: Negative elevation-dependent warming trend in the Eastern Alps, Environ. Res. Lett., 11, 044021, https://doi.org/10.1088/1748-9326/11/4/044021, 2016.

van Dongen, S.: Prior specification in Bayesian statistics: Three cautionary tales, J. Theor. Biol., 242, 90-100, https://doi.org/10.1016/j.jtbi.2006.02.002, 2006.

Veh, G., Korup, O., Roessner, S., and Walz, A.: Detecting Himalayan glacial lake outburst floods from Landsat time series, Remote Sens. Environ., 207, 84-97, https://doi.org/10.1016/j.rse.2017.12.025, 2018.

Veh, G., Korup, O., Specht, S., Roessner, S., and Walz, A.: Unchanged frequency of moraine-dammed glacial lake outburst floods in the Himalaya, Nat. Clim. Change, 2000, 1-5, https://doi.org/10.1038/s41558-019-0437-5, 2019.

Veh, G., Korup, O., and Walz, A.: Hazard from Himalayan glacier lake outburst floods, P. Natl. Acad. Sci. USA, 117, 907-912, https://doi.org/10.1073/pnas.1914898117, 2020.
Vehtari, A., Gelman, A., and Gabry, J.: Practical Bayesian model evaluation using leave-one-out cross-validation and WAIC, Stat. Comput., 27, 1413-1432, https://doi.org/10.1007/s11222-0169696-4, 2017.

Wang, W., Yao, T., Gao, Y., Yang, X., and Kattel, D. B.: A First-order Method to Identify Potentially Dangerous Glacial Lakes in a Region of the Southeastern Tibetan Plateau, Mt. Res. Dev., 31, 122-130, https://doi.org/10.1659/MRD-JOURNAL-D10-00059.1, 2011.

Wang, X., Liu, S., Guo, W., and Xu, J.: Assessment and simulation of glacier lake outburst floods for Longbasaba and Pida lakes, China, Mt. Res. Dev., 28, 310-317, https://doi.org/10.1659/mrd.0894, 2008.

Wang, X., Liu, S., Ding, Y., Guo, W., Jiang, Z., Lin, J., and Han, Y.: An approach for estimating the breach probabilities of moraine-dammed lakes in the Chinese Himalayas using remotesensing data, Nat. Hazards Earth Syst. Sci., 12, 3109-3122, https://doi.org/10.5194/nhess-12-3109-2012, 2012.

Wang, X., Guo, X., Yang, C., Liu, Q., Wei, J., Zhang, Y., Liu, S., Zhang, Y., Jiang, Z., and Tang, Z.: Glacial lake inventory of high-mountain Asia in 1990 and 2018 derived from Landsat images, Earth Syst. Sci. Data, 12, 2169-2182, https://doi.org/10.5194/essd-12-2169-2020, 2020.

Worni, R., Huggel, C., and Stoffel, M.: Glacial lakes in the Indian Himalayas - From an area-wide glacial lake inventory to on-site and modeling based risk assessment of critical glacial lakes, Sci. Total Environ., 468, S71-S84, https://doi.org/10.1016/j.scitotenv.2012.11.043, 2013.

Yang, S.-K. and Smith, G. L.: Further Study on Atmospheric Lapse Rate Regimes, J. Atmos. Sci., 42, 961-966, https://doi.org/10.1175/15200469(1985)042<0961:fsoalr>2.0.co;2, 1985. 